\title{
SEMICONDUTORES HETEROESTRUTURADOS: UMA ABORDAGEM SOBRE OS PRINCIPAIS DESAFIOS PARA A OBTENÇÃO E APLICAÇÃO EM PROCESSOS FOTOQUÍMICOS AMBIENTAIS E ENERGÉTICOS
}

\author{
Romero T. Bueno ${ }^{\mathrm{a}}$, Osmando F. Lopes ${ }^{\mathrm{b}}$, Kele T. G. Carvalho ${ }^{\mathrm{c}}$, Caue Ribeiro ${ }^{\mathrm{cd}, *, \bullet}$ e Henrique A. J. L. Mourão ${ }^{\mathrm{a}}$ \\ anstituto de Ciência e Tecnologia, Universidade Federal dos Vales do Jequitinhonha e Mucuri, 39100-000 Diamantina - MG, Brasil \\ bInstituto de Química, Universidade Federal de Uberlândia, 38400-902 Uberlândia - MG, Brasil \\ 'Laboratório Nacional de Nanotecnologia para o Agronegócio, Embrapa Instrumentação, 13561-206 São Carlos - SP, Brasil \\ ${ }^{\mathrm{d} F o r s c h u n g s z e n t r u m ~ J u ̈ l i c h ~} \mathrm{GmbH}$, Institute of Energy and Climate Research (IEK-3): Electrochemical Process Engineering. \\ 52425 Jülich, Germany
}

Recebido em 10/02/2019; aceito em 18/04/2019; publicado na web em 27/05/2019

\begin{abstract}
HETEROSTRUCTURED SEMICONDUCTORS: AN APPROACH ABOUT THE MAIN CHALLENGES FOR OBTAINING AND APPLICATION ON ENVIRONMENTAL AND ENERGY PHOTOCHEMICAL PROCESSES. Heterostructured semiconductors are materials with unique features formed by combination of two or more semiconductors with suitable interface between them. The study of the heterostructures aim the development of physico-chemical and photocatalytic properties higher than their isolated phases, which makes it possible to obtain higher efficiency and lower cost in several technological processes. Recently the heterostructured materials have been extensively used in the development of alternative technologies either for environmental pollution control or for renewable energy production, among other applications. However, the obtaining of a heterostructure with suitable features is not trivial. In this way, this review article presents a broad discussion about methods of obtaining heterostructures formed by semiconductors and their applications in the photochemical processes, mainly in the environmental field. It will be addressed the use of the heterostructures in photocatalytic application for the organic pollutants degradation, heavy metals removal, the inactivation of pathogenic microorganisms, beyond of the volatile organic compounds (VOC's) photooxidation and the photocatalytic abatement of nitrogen oxide $\left(\mathrm{NO}_{\mathrm{x}}\right)$ in gaseous phase. Finally, a discussion about the carbon dioxide $\left(\mathrm{CO}_{2}\right)$ photoreduction and hydrogen $\left(\mathrm{H}_{2}\right)$ production focusing mainly in the chemical energy production will be presented.
\end{abstract}

Keywords: semiconductor; heterostructures; photochemical processes; environmental; energy.

\section{INTRODUÇÃO}

Em 1984, como consequência dos estudos pioneiros de Nick Serpone e Michael Gratzel, foi verificado o fenômeno de transferência de cargas entre semicondutores. ${ }^{1}$ Os autores conseguiram demonstrar que o acoplamento entre $\mathrm{TiO}_{2}$ e CdS conduziu a uma notável separação das cargas fotogeradas (elétrons, e, e buracos, $\mathrm{h}^{+}$), o que promoveu a diminuição da taxa de recombinação entre elas. Nesse sistema, os e- fotogerados na banda de condução (BC) do CdS pela absorção de energia são transferidos para a $\mathrm{BC}$ do $\mathrm{TiO}_{2}$, enquanto $\mathrm{os}^{+}$fotogerados permanecem na banda de valência (BV) do CdS, que resulta na separação espacial entre o par e- $/ \mathrm{h}^{+}$e no aumento do tempo de vida destes. Desde então, a combinação de semicondutores com diferentes propriedades em um único material tem atraído muita atenção devido à possibilidade de melhorar o desempenho catalítico para uma determinada aplicação em comparação com os constituintes isolados. ${ }^{2}$

A heteroestrutura é um sistema no qual materiais de diferentes composições ou estruturas compartilham a mesma interface, denominada heterojunção. Esse sistema permite o controle de diversos parâmetros fundamentais em tecnologias envolvendo semicondutores, tais como band gap, mobilidade efetiva de portadores de massa e carga, índice de refração e outros. ${ }^{3,4}$ A heterojunção pode ser definida como a interface entre quaisquer dois materiais no estado sólido, incluindo estruturas cristalinas e amorfas de materiais semicondutores, condutores e isolantes..$^{5-7} \mathrm{O}$ comportamento de uma heteroestrutura de semicondutores depende do band gap, da afinidade eletrônica e das posições relativas das $\mathrm{BC}$ e $\mathrm{BV}$ dos semicondutores constituintes.

*e-mail: caue.ribeiro@embrapa.br
Após a publicação dos trabalhos de Fujishima e Honda ${ }^{8}$ sobre a produção de $\mathrm{H}_{2}$ - water splitting (1972) - via fotocatálise heterogênea e dos trabalhos de Serpone e Gratzel ${ }^{1}$ a respeito do aumento da atividade fotocatalítica de materiais heteroestruturados (1984), foram publicados vários trabalhos sobre a aplicação de heteroestruturas em fotocatálise. A Figura 1 mostra a evolução das publicações na área analisando a base de dados 'web of science' durante os últimos 10 anos, na qual se observa um aumento progressivo do número de publicações relacionadas ao termo heterojunção e em relação aos trabalhos envolvendo processos fotocatalíticos ativados no visível, um dos temas mais abordados na área.

Nesse sentido, este artigo abordará os processos de obtenção e as principais aplicações das heteroestruturas de semicondutores em processos fotoquímicos relacionados à área ambiental e de produção de energia. Primeiramente, serão discutidos a estrutura dos semicondutores, os diferentes tipos de heteroestruturas e as formas mais comuns de obtenção. Em seguida, serão apresentadas as aplicações envolvendo essas heteroestruturas nos tratamentos de efluentes líquidos, o que engloba a foto-oxidação de poluentes orgânicos, a remoção de metais pesados e a inativação de microorganismos patogênicos. Alguns processos fotocatalíticos em fase gasosa também serão apresentados, tais como a foto-oxidação de compostos orgânicos voláteis (COVs) e o abatimento fotocatalítico de óxidos de nitrogênio $\left(\mathrm{NO}_{\mathrm{x}}\right)$. Com relação às aplicações relacionadas à produção de energia, a fotorredução do $\mathrm{CO}_{2}$ e a produção de $\mathrm{H}_{2}$ utilizando-se semicondutores heteroestruturados serão discutidas no final deste artigo.

\section{ESTRUTURA DE SEMICONDUTORES}

De maneira geral, um material é classificado como um 


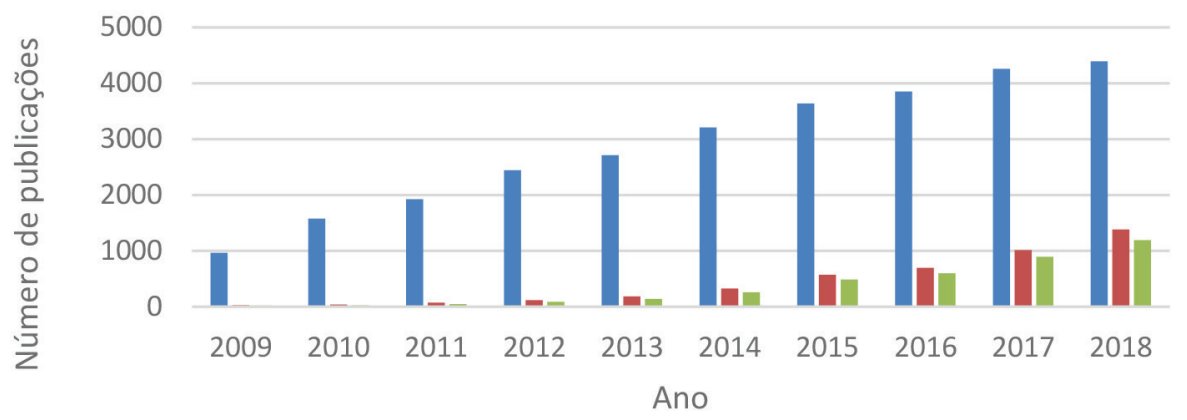

- Heterojunction

- Heterojunction photocatalytic

Heterojunction visible photocatalytic

Figura 1. Informações obtidas da 'web of science' monstrando a evolução no número das publicações entre os anos de 2009 e 2018. Busca realizada usando os termos: hererojunção (em inglês, heterojunction), fotocatalítico (photocatalytic) e visível (visible)

semicondutor quando apresenta uma resistividade elétrica à temperatura ambiente na faixa de $10^{-2}$ e $10^{9} \Omega \cdot \mathrm{cm}$, referente a valores intermediários entre bons condutores e bons isolantes. ${ }^{9}$ As características elétricas únicas desses materiais os tornam especialmente úteis na construção de dispositivos eletrônicos (diodos, transistores, células fotovoltaicas, termistores, etc.) e em aplicações envolvendo processos fotocatalíticos. ${ }^{9,10}$

As propriedades elétricas de um semicondutor resultam de sua estrutura eletrônica característica, que pode ser descrita pelo modelo das bandas de energia. ${ }^{11} \mathrm{~A}$ origem das bandas em sólidos pode ser compreendida a partir de uma extensão da teoria do orbital molecular (OM). ${ }^{11}$ De acordo com teoria OM, a combinação linear de dois orbitais atômicos dá origem a dois orbitais moleculares de energias distintas, um ligante e outro antiligante. Um sólido, no entanto, é formado pela união de um número virtualmente infinito de átomos, o que leva à superposição de orbitais adjacentes para a formação de ligações. Dessa maneira, conforme os átomos se aproximam para a formação do sólido, mais orbitais moleculares são gerados, dando origem a um conjunto de orbitais não degenerados que constituem uma banda (Figura 2). ${ }^{11,12}$

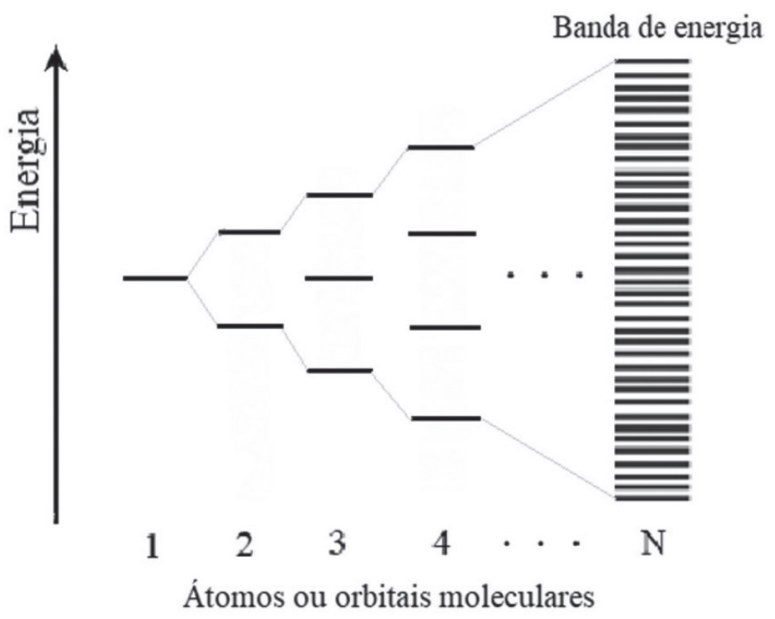

Figura 2. Formação de uma banda eletônica a partir do enfileiramento de $N$ átomos

A Figura 2 mostra a formação de uma "banda s", constituída pela sobreposição de orbitais do tipo s, sendo possível também a formação de bandas "p" e "d". Devido à diferença energética entre os orbitais ligantes e antiligantes, pode ocorrer a formação de uma falha entre as bandas, conhecida como banda proibida ou band gap
$\left(\mathrm{E}_{\mathrm{g}}\right)$. Assim, a existência da banda proibida está relacionada com a extensão das bandas consecutivas e a diferença energética dos tipos de orbitais que as constituem. ${ }^{12}$

A ocupação das bandas pode ser descrita pela função Fermi, que nos fornece a probabilidade de um estado de energia E estar ocupado por um e- livre. ${ }^{13}$

$$
f(E)=\frac{1}{1+e^{\left((E-E f) / K_{b} T\right)}}
$$

Na equação (1), T é a temperatura absoluta do sistema em Kelvin, $\mathrm{k}_{\mathrm{B}}$ é a constante de Boltzmann (aproximadamente 1,38065.10 $0^{-23} \mathrm{~J} / \mathrm{K}$ ) e $E_{\mathrm{f}}$ é o nível de Fermi. $O \mathrm{E}_{\mathrm{f}}$ é um nível energético de referência do material, sendo um parâmetro importante na predição de seu comportamento elétrico. ${ }^{14}$ De acordo com essa função, à temperatura de $0 \mathrm{~K}$, a probabilidade de ocupação de um estado com energia inferior ao $\mathrm{E}_{\mathrm{f}}$ é de $100 \%$ ( $\mathrm{f}=1$ ). Por outro lado, para níveis com energia superior ao $\mathrm{E}_{\mathrm{f}}$, a possibilidade de ocupação é nula. À medida que a temperatura aumenta, os e- podem adquirir energia suficiente para ocupar estados energéticos acima do nível de Fermi. ${ }^{13}$

A condutividade em sólidos resulta da mobilidade de portadores de carga, em resposta a um campo elétrico aplicado. ${ }^{9}$ A Figura 3 traz uma representação esquemática da estrutura de metais, isolantes e semicondutores a $0 \mathrm{~K}$. Em metais, geralmente há uma sobreposição de bandas (Figura 3a). Assim, os e- da BV podem transitar com facilidade para a BC com a adição de pouca energia ou aplicação de um campo elétrico. As estruturas de semicondutores e isolantes são semelhantes por apresentarem a BV totalmente preenchida e a $\mathrm{BC}$ totalmente vazia (Figuras $3 \mathrm{~b}$ e $3 \mathrm{c}$ ). A diferença está na largura

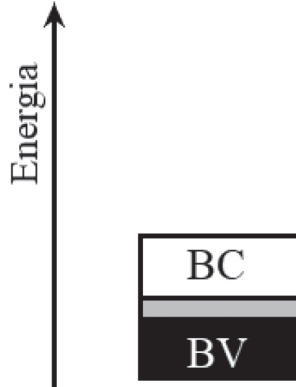

(a)

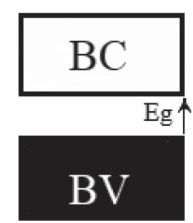

(b)

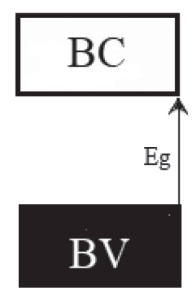

(c)
Figura 3. Diagramas de bandas típicos para a) metais; b) semicondutores ec) isolantes a $0 \mathrm{~K}$ 
da $E_{g}$, que é mais estreita nos semicondutores. Desse modo, nos semicondutores alguns estados inferiores na $\mathrm{BC}$ são mais acessíveis para $\mathrm{e}^{-}$do topo da $\mathrm{BV}$ à temperaturas superiores a $0 \mathrm{~K} .^{15}$

Em um semicondutor de elevada pureza, a condução pode se dar de maneira intrínseca, ou seja, pela promoção de e- da BV para a BC. Além de introduzir portadores de carga negativos no nível superior, essa ocupação gera $\mathrm{h}^{+}$no nível inferior. Esses são considerados como portadores de carga positivos e também contribuem para o processo de condução. Os dois semicondutores intrínsecos mais conhecidos são o silício $(\mathrm{Si})$ e o germânio $(\mathrm{Ge})$, ambos do grupo 14 da tabela periódica. Certos compostos semicondutores também podem exibir comportamento intrínseco. Entre estes, estão os compostos formados pela união de elementos do grupo 13 com elementos do grupo 15 , como por exemplo, o arseneto de gálio ( $\mathrm{GaAs})$ e o antimoneto de índio (InSb). ${ }^{15,16}$

O comportamento elétrico de um semicondutor pode ser ditado também pela presença de impurezas. Nesses casos, diz-se que o material apresenta semicondução extrínseca. Por exemplo, quando um átomo de valência 5 é adicionado como uma impureza substitucional em uma rede composta por átomos de silício (tetravalentes), apenas quatro dos cinco e- desses átomos de impureza podem participar de ligações, pois existem apenas quatro ligações possíveis com átomos vizinhos. Dessa forma, o e- que não forma ligações fica preso fracamente em torno do átomo de impureza, através de uma ligação eletrostática fraca. Pela perspectiva do modelo de bandas eletrônicas, cada um desses e- fracamente ligado ocupa um único nível de energia, localizado dentro do espaçamento proibido entre as bandas, próximo da borda inferior da BC (Figura 1Sa). A energia necessária para excitar o e- desde um desses estados de impureza até um estado dentro da $\mathrm{BC}$ é a própria energia de ligação do e-. Em casos assim, em que as impurezas são doadoras de $\mathrm{e}^{-}$, a semicondução é dita extrínseca do tipo n. Além disso, observa-se uma aproximação do nível de Fermi com o estado doador. ${ }^{15,16}$

Adicionando impurezas substitucionais do grupo 3 ao silício, tais como o boro e o alumínio, um efeito oposto é produzido. Nesse caso, uma das ligações covalentes ao redor de cada átomo se torna deficiente de $\mathrm{e}^{-}$, sendo tal deficiência conhecida como buraco ou lacuna, que aqui nos referimos como $\mathrm{h}^{+}$. Como o $\mathrm{h}^{+}$é fracamente ligado ao átomo de impureza, este pode ser liberado pela transferência de $\mathrm{e}^{-} \mathrm{de}$ uma ligação adjacente. Assim, o h ${ }^{+}$e o e- podem trocar de posições, de modo que $\mathrm{o} \mathrm{h}^{+}$em movimento (estado excitado) contribui para o processo de condução. Para esse tipo de semicondução extrínseca, os $\mathrm{h}^{+}$são os principais responsáveis pela condução por estarem presentes em grande concentração. Sob essas circunstâncias, o semicondutor é classificado como sendo do tipo p. Átomos de impurezas desse tipo introduzem um nível de energia dentro do espaçamento entre as bandas, localizado próximo da borda superior da BV (Figura 1Sb).
Em semicondutores do tipo p, o nível de Fermi permanece dentro do espaçamento entre as bandas, porém próximo do estado receptor. ${ }^{15,16}$

\section{HETEROESTRUTURAS DE SEMICONDUTORES}

\section{Tipos de heteroestruturas}

A combinação de diferentes semicondutores resulta em diferentes tipos de heteroestruturas dependendo das suas características eletrônicas, sendo cada tipo mais apropriado para aplicações específicas. A adequação de uma heteroestrutura para um determinado processo está diretamente relacionada ao sentido da migração de cargas na interface de conexão entre os materiais, que ocorre devido à diferença de energia potencial das BC e BV em cada estrutura. ${ }^{17}$

As heteroestruturas são classificadas em três tipos de acordo com a relação entre as bandas de energia dos materiais constituintes, como ilustrados na Figura 4. Para a heteroestrutura do tipo I, a BC e a BV de um dos semicondutores são respectivamente superior e inferior às bandas correspondentes do outro semicondutor. Portanto, sob irradiação de luz, os e- e $\mathrm{h}^{+}$se acumulam nos níveis das BC e BV do semicondutor com menor $\mathrm{E}_{\mathrm{g}}$. Como os e- e os $\mathrm{h}^{+}$se acumulam no mesmo semicondutor, não podem ser efetivamente separados, portanto, não é adequada para aplicação em fotocatálise. ${ }^{18} \mathrm{Na}$ heteroestrutura do tipo II, a migração de cargas fotogeradas pode ocorrer em sentidos opostos, isto é, os e- são acumulados em um semicondutor, enquanto $o s \mathrm{~h}^{+}$são acumulados no outro semicondutor. Esse fenômeno ocorre devido à relação entre as bandas dos semicondutores, e principalmente devido aos seus níveis de Fermi. Essa separação espacial impede a rápida recombinação das cargas fotogeradas. Um semicondutor com posições de bandas apropriadas atua como sequestrador de $\mathrm{e}^{-} \mathrm{e} \mathrm{h}^{+}$, permitindo que estas cargas possam reagir separadamente. ${ }^{19} \mathrm{~A}$ arquitetura da heteroestrutura do tipo III é similar àquela da heteroestrutura do tipo II, porém não há sobreposição dos band gap's, sendo assim inadequada para aplicações fotocatalíticas.

Existem ainda outros tipos de heteroestruturas, tais como, o tipo p-n, esquema-Z e junção Schottky (Figura 5). Uma heterojunção p-n é formada pela combinação de um semicondutor do tipo p com outro do tipo n. Nesse tipo de heteroestrutura, antes da irradiação de luz, os e $\mathrm{e}^{-}$do semicondutor do tipo $\mathrm{n}$ tendem a difundir-se através da interface $\mathrm{p}$-n para o semicondutor do tipo $\mathrm{p}$, deixando uma espécie carregada positivamente. Enquanto isso, os $\mathrm{h}^{+}$do semicondutor do tipo $\mathrm{p}$ tendem a difundir-se para o semicondutor do tipo n, deixando uma espécie carregada negativamente. A difusão dos $\mathrm{e}^{-} \mathrm{e} \mathrm{h}^{+}$continuará até que o equilíbrio do nível de Fermi do sistema seja alcançado. Como resultado, um campo elétrico interno é gerado na região próxima à interface $\mathrm{p}-\mathrm{n}$. Os $\mathrm{e}^{-} \mathrm{e}^{+}$fotogerados nos semicondutores do tipo $\mathrm{p}$ e n migrarão sob a influência do campo elétrico interno para a $\mathrm{BC}$

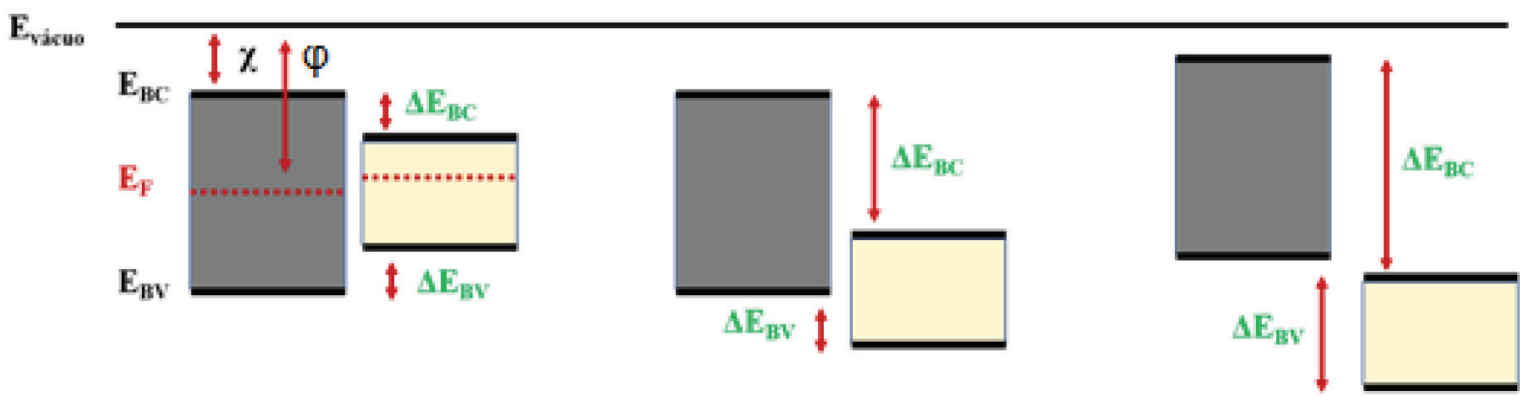

Figura 4. Diferentes tipos de heterojunções entre semicondutores. $E_{\text {vácuo }}$ é o ponto de referência de energia (i.e. vácuo); $E_{B C}$ é a energia da BC; $E_{B V}$ é a energia da $B V ; E_{F}$ denota energia de Fermi; $\varphi$ é a função trabalho e $\chi$ retrata a eletroafinidade 


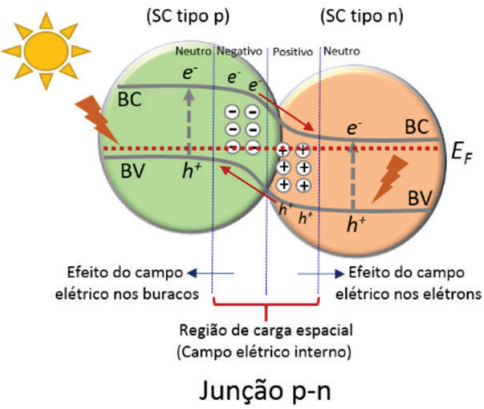

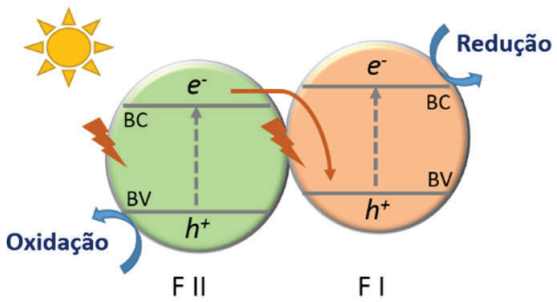

Esquema-Z direto

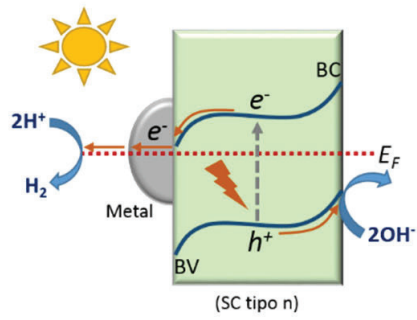

Junção Schottky

Figura 5. Ilustração esquemática da separação de cargas fotogeradas: em uma heterojunção p-n; em um esquema-Z direto; e em uma junção Schottky

do semicondutor do tipo $\mathrm{n}$ e para a BV do semicondutor do tipo $\mathrm{p}$, respectivamente, o que resulta na separação espacial e aumento do tempo de vida das cargas.

A junção Schottky, por sua vez, é formada por um metal disperso sobre um semicondutor do tipo n ou p, e é comumente utilizada para induzir a separação de carga efetiva em dispositivos optoeletrônicos, fotocatalisadores ou células fotoeletroquímicas. ${ }^{19,20}$ Nesse sistema, assim como nas heteroestruturas do tipo p-n, gera-se um campo elétrico que facilita a separação dos e e $\mathrm{h}^{+}$fotogerados. Na maioria dos trabalhos na literatura essa estrutura é referida apenas como um fotocatalisador com um co-catalisador depositado na sua superfície.

Embora todos os tipos de heterojunções mencionados sejam eficientes para melhorar a separação dos $\mathrm{e}^{-} \mathrm{e}^{+} \mathrm{h}^{+}$fotogerados, a capacidade de oxirredução da heteroestrutura é diminuída já que os processos de redução e oxidação ocorrerão no semicondutor com os menores potenciais de redução e oxidação, respectivamente. Para superar esse problema, o conceito fotocatalítico do esquema- $Z$ foi proposto por Allen J. Bard em 1979 para maximizar o potencial redox dos sistemas de heterojunção. ${ }^{21} \mathrm{Um}$ sistema fotocatalítico com esquema-Z convencional é composto por dois semicondutores, fotocatalisador I (FI) e fotocatalisador II (FII), e um par aceitador/doador de e- (A/D). FI e FII não são colocados em contato físico. Durante a reação fotocatalítica, os $\mathrm{e}^{-}$fotogerados migram da BC do FII, com o maior potencial de oxidação, para a BV do FI, com o maior potencial de redução, através do par A/D conforme as seguintes reações redox:

$$
\begin{aligned}
& \mathrm{A}+e^{-} \rightarrow \mathrm{D} \\
& \mathrm{D}+h^{+} \rightarrow \mathrm{A}
\end{aligned}
$$

Especificamente, A é reduzido em D (ou simplesmente $\mathrm{A}^{-}$) ao reagir com os $\mathrm{e}^{-}$fotogerados da $\mathrm{BC}$ do FII, e em seguida, $\mathrm{D}\left(\mathrm{A}^{-}\right)$é oxidado em A pelo $\mathrm{h}^{+}$da BV do FI. Desta forma, os e- se acumulam no FI e os $\mathrm{h}^{+}$se acumulam no FII simultaneamente. Como resultado, uma maior separação espacial dos portadores de carga e uma elevada capacidade de oxirredução podem ser alcançadas. No entanto, os sistemas fotocatalíticos convencionais com esquema-Z só podem ser construídos em fase líquida, limitando assim a sua aplicação em fotocatálise.

Em 2006, Tada e colaboradores ${ }^{22}$ propuseram o conceito de um sistema fotocatalítico com esquema- $Z$ no estado sólido constituído por dois semicondutores diferentes $\mathrm{FI}(\mathrm{CdS})$ e FII $\left(\mathrm{TiO}_{2}\right)$ e um mediador sólido de e- entre eles (Au). Nessa arquitetura, os e- fotogerados no FII migram para a BV do FI através do mediador de e- e são novamente excitados, mas desta vez para a BC do FI. Como resultado, os $\mathrm{h}^{+}$fotogerados são acumulados no FII, promovendo a separação espacial dos portadores de carga e a otimização do potencial de oxirredução. Esse tipo de esquema-Z no estado sólido possui a vantagem adicional de poder ser usado em meios aquosos, gasosos e sólidos, estendendo assim sua aplicação em sistemas fotocatalíticos. Entretanto, os mediadores de e- necessários para conduzir a migração dos e` no esquema-Z são caros e raros, o que pode limitar as aplicações em grande escala desses fotocatalisadores.

Em comparação com a heterojunção do tipo II (Figura 4), o esquema-Z direto (Figura 5) possui a mesma configuração de estrutura de bandas, mas um modo de transferência dos portadores de carga diferente. No esquema- $Z$ direto, a presença de mediadores de e- não é necessária para que ocorra a transferência de e e. $^{-22}$ Assim, os $\mathrm{e}^{-}$fotogerados com elevado potencial de redução na BC do FI e os $\mathrm{h}^{+}$com elevado potencial de oxidação na BV do FII são preservados, enquanto os $\mathrm{e}^{-}$fotogerados na $\mathrm{BC}$ do FII e os $\mathrm{h}^{+}$na BV do FI com poder de oxirredução inferior se recombinam. Como resultado, o esquema- $Z$ direto possui simultaneamente um alto poder de oxirredução para conduzir reações fotocatalíticas e uma efetiva separação espacial dos portadores de carga.

\section{Desafios na obtenção e processamento de heteroestruturas}

O desafio mais importante no desenvolvimento de heteroestruturas eficientes para aplicações distintas é a definição de quais semicondutores devem ser combinados para exibir uma vida útil maximizada dos portadores de carga e, simultaneamente, apresentar posições apropriadas de BV e BC para conduzir reações específicas de oxirredução fotoativadas. É possível propor uma combinação de semicondutores que pode resultar em uma propriedade fotocatalítica ótima baseando-se em conhecimentos teóricos. Entretanto, obter experimentalmente heterojunções efetivas entre estes semicondutores é um grande desafio. Além disso, a condição (ex.: pH, temperatura, etc.) necessária para obter um dos semicondutores pode não ser favorável para a obtenção do outro semicondutor constituinte da heteroestrutura. Nesse sentido, ainda são necessários grandes esforços para desenvolver métodos de síntese para obter heteroestruturas com junções apropriadas e que apresentem as propriedades físico-químicas desejadas.

Numerosos métodos de síntese têm sido aplicados para se obter heteroestruturas de diferentes semicondutores, tais como os métodos sol-gel, dos precursores poliméricos e hidrotérmico. ${ }^{23-28}$ No entanto, as variações mais importantes na obtenção de heteroestruturas não residem no método em si, mas sim na estratégia utilizada, como por exemplo o crescimento simultâneo de duas fases no meio reacional, o crescimento de uma fase sobre uma segunda fase pré-formada ou a utilização de ambas as fases pré-formadas como blocos de construção. Cada uma dessas estratégias possui vantagens e desvantagens relacionadas à facilidade de obtenção das fases conjuntas, custo e controle das propriedades morfológicas, estruturais e eletrônicas, como serão apresentadas a seguir.

\section{Obtenção de heteroestruturas por crescimento simultâneo das fases}

O crescimento simultâneo permite que a heteroestrutura seja obtida em apenas uma etapa de síntese, sendo essa a principal vantagem, 
especialmente quando se considera a viabilidade da rota sintética para plantas industriais. ${ }^{29-32}$ Entretanto, esse processo além de requerer que as fases sejam formadas em condições similares, pode levar à formação de fases segregadas, dopagem indesejada, além do baixo controle morfológico.

O método dos precursores poliméricos é uma rota sintética capaz de obter heteroestruturas via cristalização simultânea. Esse método se baseia na formação de uma rede de polímeros tridimensionais que mantem os cátions dispersos de forma homogênea em toda a sua estrutura, impedindo a precipitação de óxido/hidróxido e a separação de fases na etapa de calcinação. ${ }^{24}$ Castro e colaboradores, ${ }^{29}$ por exemplo, sintetizaram heteroestruturas de $\mathrm{TiO}_{2} / \mathrm{WO}_{3}$ com propriedades físico-químicas superiores àquelas apresentadas pelas fases individuais ou pela mistura física.

Mourão e colaboradores ${ }^{5}$ avaliaram a formação de heteroestruturas por cristalização simultânea de $\mathrm{TiO}_{2} / \mathrm{SnO}_{2}$ em soluções alcalinas sob condições hidrotérmicas. Os autores observaram que a heteroestrutura foi eficientemente formada em determinadas condições, mas que em meio altamente alcalino formou-se somente $\mathrm{TiO}_{2}$. Estratégia similar foi adotada por diferentes autores para se obter diferentes heteroestruturas de forma simultânea com elevada atividade fotocatalítica, tais como, $\mathrm{CdS} / \mathrm{SnO}_{2},{ }^{31} \mathrm{Ag} / \mathrm{ZnO},{ }^{32} \mathrm{CdS} / \mathrm{TiO}_{2}{ }^{33}$

Junções formadas entre as fases polimórficas de um mesmo semicondutor também podem ser obtidas através de cristalização simultânea, como demonstrado pela síntese de heteroestruturas das fases rutilo e anatase do $\mathrm{TiO}_{2}$ via processo hidrotérmico. ${ }^{34} \mathrm{~A}$ sinergia decorrente da coexistência das fases anatase e rutilo promoveu um melhoramento das propriedades físico-químicas em comparação com as fases puras. ${ }^{35} \mathrm{Em}$ um trabalho similar, a síntese de uma heteroestrutura a partir das fases monoclínica e tetragonal do $\mathrm{BiVO}_{4}$ foi proposta por Lopes e colaboradores ${ }^{36}$ usando uma estratégia de crescimento de fase simultânea por cristalização hidrotérmica. A quantidade de heterojunções entre as fases do $\mathrm{BiVO}_{4}$ foi controlada pelos parâmetros da reação, o que promoveu o aumento do tempo de vida dos portadores de carga. Similarmente, Liu e colaboradores ${ }^{37}$ prepararam uma heteroestrutura por um método de uma única etapa entre duas fases de $\mathrm{g}-\mathrm{C}_{3} \mathrm{~N}_{4}$ (cristalina e amorfa). A formação da heteroestrutura permitiu ajustar o nível de energia dos constituintes e resultou em um alto desempenho fotocatalítico.

Apesar das vantagens apresentadas pela cristalização simultânea, ainda são necessários estudos sistemáticos para propor estratégias de síntese mais eficientes para assegurar o controle da proporção desejada entre os semicondutores, assim como o controle das suas características físico-químicas e eletrônicas, principalmente na produção em maior escala. ${ }^{38,39}$

\section{Obtenção de heteroestruturas pelo crescimento de uma fase sobre outra pré-formada}

A cristalização de uma fase sobre outra pré-formada minimiza a ocorrência de dopagem e proporciona um elevado controle da composição e da morfologia de pelo menos uma das fases constituintes da heteroestrutura. Esta abordagem foi utilizada com sucesso no crescimento de $\mathrm{SnO}_{2}$ via métodos sol-gel hidrolítico e precursores poliméricos sobre o $\mathrm{TiO}_{2}$ pré-formado. ${ }^{17} \mathrm{~A}$ utilização de ambos os métodos permitiu um controle morfológico e a formação de heterojunções de forma efetiva, resultando no aumento da atividade fotocatalítica das heteroestruturas em comparação com as fases puras de $\mathrm{SnO}_{2}$ e $\mathrm{TiO}_{2}$.

Outro exemplo interessante é o uso do método hidrotérmico para precipitar uma fase sobre um material pré-formado, como mostrado por Carvalho e colaboradores ${ }^{40}$ na obtenção das heteroestruturas de g- $\mathrm{C}_{3} \mathrm{~N}_{4} / \mathrm{Nb}_{2} \mathrm{O}_{5}$ a partir do crescimento das nanopartículas de $\mathrm{Nb}_{2} \mathrm{O}_{5}$ sobre a superfície de $\mathrm{g}-\mathrm{C}_{3} \mathrm{~N}_{4}$ pré-formado. As heteroestruturas apresentaram dispersão homogênea das partículas de $\mathrm{Nb}_{2} \mathrm{O}_{5}$ sobre o g- $\mathrm{C}_{3} \mathrm{~N}_{4}$, o que resultou em propriedades fotocatalíticas superiores em comparação com as fases puras de $\mathrm{g}_{-} \mathrm{C}_{3} \mathrm{~N}_{4} \mathrm{e} \mathrm{Nb}_{2} \mathrm{O}_{5}$. Uma estratégia semelhante foi relatada por Nossol e colaboradores ${ }^{41}$ na obtenção de heteroestruturas entre $\mathrm{TiO}_{2}$ e óxido de grafeno (GO). Nesse estudo, o crescimento de $\mathrm{TiO}_{2}$ sobre a superfície do GO pré-formado foi realizado pelo método sol-gel. Essa heteroestrutura apresentou atividade fotocatalítica superior ao $\mathrm{TiO}_{2}$ comercial $\mathrm{P} 25$ na degradação do corante preto reativo 5 .

Recentemente, foi relatada uma estratégia de cristalização de uma fase sobre a superfície de outra pré-formada contendo pelo menos um elemento metálico em comum com a fase a ser cristalizada, forçando a formação de junções entre os semicondutores. Nesse processo, os metais presentes na superfície das partículas da fase pré-formada atuam como reagente para o crescimento da segunda fase, sendo a diferença de solubilidade entre as duas fases a força motriz para o crescimento da segunda. Por exemplo, as nanopartículas de $\mathrm{BiVO}_{4}$ podem ser formadas na superfície de $\mathrm{Bi}_{2} \mathrm{O}_{3}$ pré-formado, usando-se o princípio de que $\mathrm{BiVO}_{4}$ é menos solúvel que o $\mathrm{Bi}_{2} \mathrm{O}_{3}$. Essa estratégia também é útil para utilizar a morfologia da fase pré-formada como um template para a morfologia da heteroestrutura. Para o sistema $\mathrm{BiVO}_{4} / \mathrm{Bi}_{2} \mathrm{O}_{3}$, a quantidade de junções foi ajustada pelos parâmetros de síntese (ex.: temperatura, concentração de precursor, etc.) e pelo tamanho de partícula do $\mathrm{Bi}_{2} \mathrm{O}_{3}$ pré-formado. Esse método foi eficiente na obtenção de heteroestruturas do tipo II, uma vez que observou-se o aumento do tempo de vida dos portadores de carga devido à separação espacial efetiva. ${ }^{42}$ Estratégia similar foi utilizada por outros autores para obter diferentes tipos de heteroestruturas, tais como, $\mathrm{BiSiO}_{5} /$ $\mathrm{Bi}_{2} \mathrm{MoO}_{6},{ }^{43} \mathrm{AgBr} / \mathrm{Ag}_{2} \mathrm{O},{ }^{44} \mathrm{Bi}_{2} \mathrm{~S}_{3} / \mathrm{Bi}_{2} \mathrm{MoO}_{6} .{ }^{45}$

\section{Obtenção de heteroestruturas usando fases pré-formadas}

A principal vantagem desse método é o controle morfológico e estrutural envolvido na síntese de partículas de uma única fase, que podem ser usadas como blocos de construção para formar heteroestruturas. Esse processo ocorre através de coalescência orientada por colisão de partículas, onde as heterojunções são criadas por alinhamento cristalográfico. Tal mecanismo requer que ambas as fases tenham planos cristalográficos semelhantes. Heteroestruturas de $\mathrm{g}-\mathrm{C}_{3} \mathrm{~N}_{4} / \mathrm{Nb}_{2} \mathrm{O}_{5}$ foram sintetizadas pela técnica de heteroagregação induzida pela diferença das cargas superficiais das fases pré-formadas de $g-\mathrm{C}_{3} \mathrm{~N}_{4}$ e $\mathrm{Nb}_{2} \mathrm{O}_{5}$ e pelo tratamento sonoquímico, que intensifica a colisão entre as fases. ${ }^{46} \mathrm{~A}$ formação de heteroestruturas foi demonstrada pelo aumento do tempo de vida dos portadores de carga por meio da técnica de fotoluminescência resolvida no tempo.

Estratégias similares foram utilizadas em outros trabalhos para a obtenção de heteroestruturas por meio da heteroagregação das duas fases pré-formadas, tais como, $\mathrm{Bi}_{2} \mathrm{~S}_{3} / \mathrm{CdS},{ }^{47} \mathrm{BiOI} / \mathrm{TiO}_{2},{ }^{38}$ óxido de grafeno reduzido $(\mathrm{RGO}) / \mathrm{ZnO} \cdot{ }^{48}$ Esses sistemas apresentaram um alto potencial de aplicação em processos fotocatalíticos e demonstraram a eficiência e a versatilidade desse método de síntese.

\section{SEMICONDUTORES HETEROESTRUTURADOS EM PROCESSOS FOTOQUÍMICOS}

\section{Tratamento de efluentes líquidos}

\section{Foto-oxidação de poluentes orgânicos}

A descontaminação de águas residuais constitui um grande desafio técnico para a comunidade científica, empresas e governos. A presença e a diversidade de poluentes orgânicos em efluentes oriundos de atividades industriais, agrícolas e domésticas representam um sério risco à saúde pública e também aos ecossistemas. Muitos desses compostos apresentam natureza tóxica e características físico-químicas que os tornam resistentes aos processos de tratamento 
convencionais das estações de tratamento de esgoto (ETE's) e águas (ETA's) ${ }^{49}$ Assim, o desenvolvimento de métodos para tratamento de efluentes que complementem ou substituam os tratamentos convencionais se torna fundamental para a garantia da qualidade da água e o cumprimento das exigências legais.

Nesse cenário, a fotocatálise com semicondutores vem ganhando destaque por promover a degradação de uma variada classe de poluentes orgânicos. ${ }^{50} \mathrm{O}$ processo fotocatalítico tem início com a fotoativação do semicondutor, que ocorre quando um fóton com energia (hv) igual ou superior à energia $\mathrm{E}_{\mathrm{g}}$ incide sobre sua superfície (Figura 6). Como consequência, um e é promovido da $\mathrm{BV}$ para a $\mathrm{BC}$, gerando $\mathrm{um}^{+}$na BV. Os e da $\mathrm{BC}$ são bons redutores, com potenciais variando de $+0,5 \mathrm{~V}$ a $-1,5 \mathrm{~V}$ vs EPH (Eletrodo Padrão de Hidrogênio), enquanto que os $\mathrm{h}^{+}$formados na $\mathrm{BV}$ são poderosos oxidantes com potenciais entre $+1,0 \mathrm{~V} \mathrm{e}+3,5 \mathrm{~V}$ vs $\mathrm{EPH}$, dependendo do material e das condições do meio. ${ }^{51}$ Dessa forma, $\mathrm{BV}$ e $\mathrm{BC}$ podem atuar como aceptores ou doadores de $\mathrm{e}^{-}$, respectivamente, de espécies adsorvidas na superfície do semicondutor. ${ }^{52}$

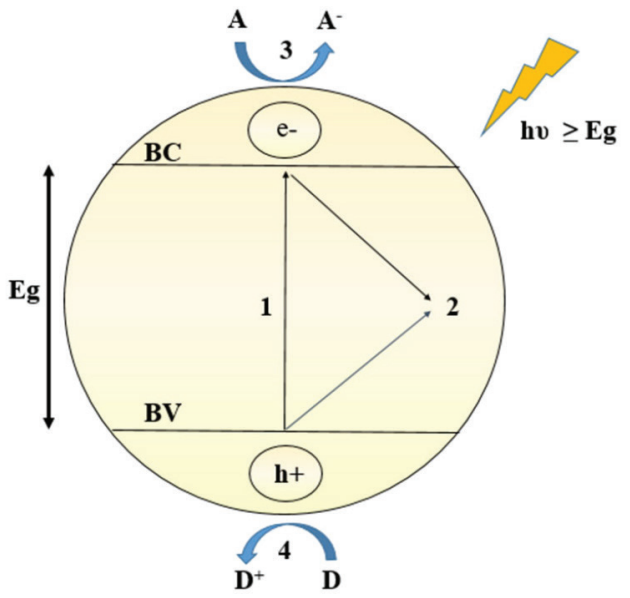

Figura 6. Mecanismo da fotocatálise heterogênea: 1) excitação do e- da $B V$ para a $B C$; 2) recombinação do par $e^{-/} h^{+}$; 3) transferência do e- da $B C$ para uma molécula aceptora (A) adsorvida na superfície do semicondutor; 4) transferência eletrônica de uma molécula doadora (D) para o $h^{+}$da BV

A fotodegradação de compostos orgânicos pode ocorrer por via direta e/ou indireta. ${ }^{53}$ Após a geração do par $\mathrm{e}^{-} / \mathrm{h}^{+}$, moléculas do poluente adsorvidas na superfície do fotocatalisador podem reagir diretamente com o $\mathrm{h}^{+}$, gerando radicais orgânicos que podem sofrer reações de degradação subsequentes. Na oxidação indireta, radicais livres são formados a partir da transferência eletrônica de grupos superficiais adsorvidos, tais como moléculas de água $\left(\mathrm{H}_{2} \mathrm{O}\right)$ e grupos hidroxilas $\left({ }^{-} \mathrm{OH}\right)$. Esses radicais, com destaque para os radicais hidroxila $\left({ }^{\circ} \mathrm{OH}\right)$, possuem baixa seletividade e alto poder oxidante, podendo assim reagir facilmente com o poluente. Em ambos os casos, reações em cadeia são iniciadas, podendo resultar na completa oxidação do poluente a $\mathrm{CO}_{2}, \mathrm{H}_{2} \mathrm{O}$ e minerais ou na degradação parcial com a formação de subprodutos. ${ }^{54}$

Nas reações em fase aquosa, as reações de formação dos radicais 'OH são consideradas as mais relevantes. ${ }^{54} \mathrm{~A}$ capacidade do semicondutor de gerar radicais ${ }^{\circ} \mathrm{OH}$ é governada, entre outros fatores, pelo potencial de redução de sua BV. Caso este seja mais positivo que o potencial necessário para a ocorrência da reação $\left(\mathrm{OH}_{\mathrm{ads}} /^{\circ} \mathrm{OH}_{\mathrm{ads}}=1,6 \mathrm{~V}\right.$ vs EPH), os radicais poderão ser formados..$^{55}$

O tempo de vida das cargas fotogeradas é um fator essencial para a eficiência fotocatalítica e deve ser suficiente para que as reações redox responsáveis pela geração dos radicais ocorram. Nesse sentido, a presença de moléculas "sequestrantes" passíveis de redução pelos $\mathrm{e}^{-}$excitados é fundamental para evitar a recombinação do par e $\mathrm{e}^{-} / \mathrm{h}^{+}$. $\mathrm{O}$ principal agente receptor de e em meio aquoso é o oxigênio $\left(\mathrm{O}_{2}\right)$. No entanto, para que a reação ocorra $\left(\mathrm{O}_{2} / \mathrm{O}_{2}{ }^{-}=-0,33 \mathrm{~V}\right.$ vs EPH) é necessário que o potencial da $\mathrm{BC}$ do semicondutor seja negativo o suficiente para tal. ${ }^{55}$ Estratégias como a dopagem metálica, ${ }^{56}$ utilização de reagentes de sacrifício, ${ }^{57}$ controle nanocristalino ${ }^{58}$ e a formação de heteroestruturas ${ }^{59}$ também têm sido utilizadas com o objetivo de prevenir a recombinação.

A Figura 7 mostra as posições das bandas em relação ao vácuo e ao eletrodo padrão de hidrogênio (EPH), bem como o band gap de alguns semicondutores. ${ }^{53}$

$\mathrm{O} \mathrm{TiO}_{2}$ na fase cristalina anatase é um dos semicondutores com características de bandas adequadas tanto para geração de radicais -OHquanto para redução do $\mathrm{O}_{2}$. Por esse e outros motivos, tal como sua fotoestabilidade, o $\mathrm{TiO}_{2}$ tem apresentado os melhores resultados. ${ }^{60}$ No entanto, em razão de seu band gap elevado $(3,2 \mathrm{eV})$, sua fotoativação ocorre somente sob irradiação UV. Assim, como apenas uma pequena parte do espectro solar é constituído por radiação $U V{ }^{61}$ a atividade fotocatalítica do $\mathrm{TiO}_{2}$, assim como a de outros semicondutores com band gap elevado (ex.: $\mathrm{ZnO}, \mathrm{SnO}_{2}, \mathrm{SrTiO}_{3}, \mathrm{Nb}_{2} \mathrm{O}_{4}$ ), é pequena sob irradiação solar.

Nesse contexto, as heteroestruturas vêm sendo estudadas com o objetivo de aumentar a eficiência do processo fotocatalítico pela diminuição da recombinação das cargas fotogeradas, entre outras propriedades melhoradas em relação aos seus componentes puros, e proporcionar a ativação de semicondutores na faixa do visível. ${ }^{62-64} \mathrm{O}$ desenvolvimento de heteroestruturas de semicondutores,

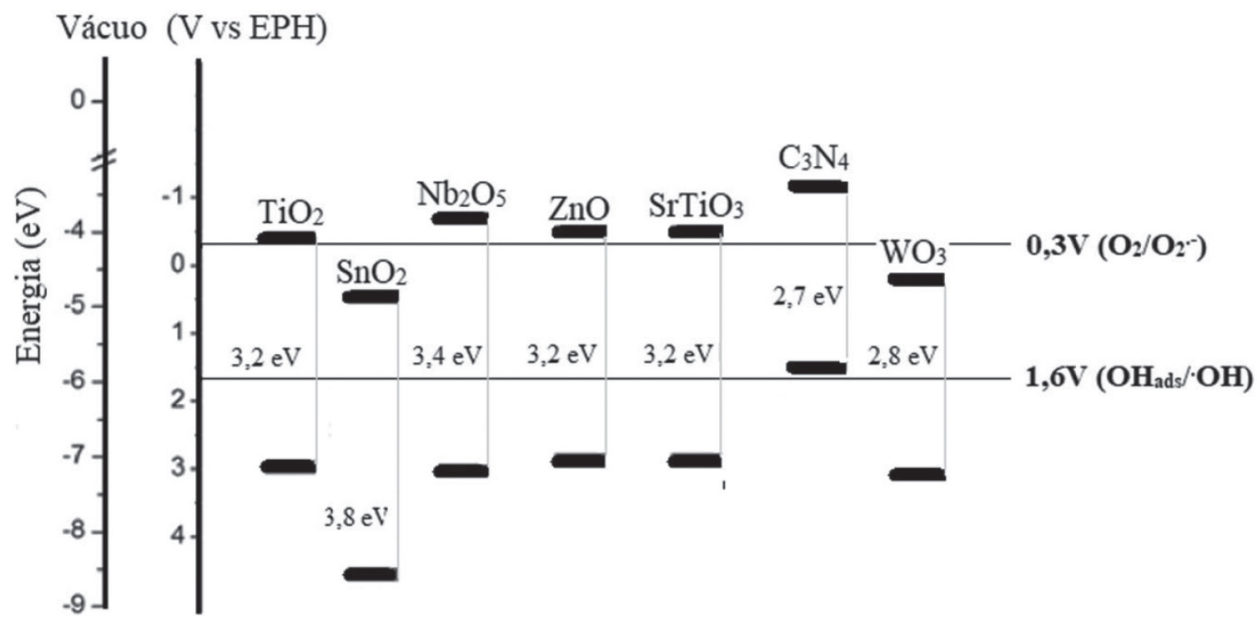

Figura 7. Posições das bandas e band gap de alguns semicondutores 
especialmente com atividade sob irradiação visível, é um dos principais temas estudados na área de fotocatálise atualmente. Vários estudos já demonstraram a melhoria da atividade fotocatalítica dos materiais heteroestruturados em relação às fases puras na degradação de corantes ${ }^{65-68}$ pesticidas ${ }^{69,70}$ e fármacos ${ }^{71,72}$ sob luz visível.

Por exemplo, Wang e colaboradores ${ }^{62}$ reportaram a síntese de $\mathrm{Ag}_{3} \mathrm{VO}_{4}$ depositado em nanofolhas de $\mathrm{BiOCl}$ pelo método hidrotérmico. Os resultados obtidos mostraram que a heteroestrutura de $\mathrm{BiOCl}-$ $\mathrm{Ag}_{3} \mathrm{VO}_{4}$ apresentou área superficial e atividade fotocatalítica maiores que os materiais puros sob irradiação visível. Lin e colaboradores ${ }^{73}$ reportaram a montagem da nanoheteroestruturas de $\mathrm{InVO}_{4} / \mathrm{BiVO}_{4}$ com atividade fotocatalítica sob irradiação visível, sendo observada também uma maior separação das cargas $\mathrm{e}^{\mathrm{e}} / \mathrm{h}^{+}$.

Recentemente, Lu e colaboradores ${ }^{74}$ apresentaram a síntese de heteroestruturas do tipo p-n de $\mathrm{Bi}_{2} \mathrm{O}_{3} / \mathrm{Bi}_{2} \mathrm{SiO}_{5}$ por um método de calcinação simultânea dos precursores à $600{ }^{\circ} \mathrm{C} / 4 \mathrm{~h}$. Essas heteroestruturas apresentaram ampliação da banda de absorção de radiação para região do visível e elevada atividade fotocatalítica na degradação de poluentes orgânicos sob irradiação solar simulada. $\mathrm{O}$ aumento da fotoatividade foi atribuído principalmente ao aumento da área superficial e a ampliação da banda de absorção. Liu e colaboradores ${ }^{75}$ também sintetizaram a heteroestrutura de $\mathrm{Bi}_{2} \mathrm{SiO}_{5} / \mathrm{BiPO}_{4}$ via rota hidrotérmica. Os resultados revelaram que o desempenho fotocatalítico superior das heteroestruturas de $\mathrm{Bi}_{2} \mathrm{SiO}_{5} / \mathrm{BiPO}_{4}$ foi devido principalmente ao aumento da separação das cargas pela presença da heterojunção, aumento da cristalinidade, ampliação da absorção de radiação, entre outros.

$\mathrm{O}$ nitreto de carbono grafítico $\left(\mathrm{g}-\mathrm{C}_{3} \mathrm{~N}_{4}\right)$ é um semicondutor orgânico que vem se destacando em aplicações fotocatalíticas principalmente por ser ativado sob luz visível, pois apresenta valor de $E_{\mathrm{g}}$ de aproximadamente $2,7 \mathrm{eV}(\lambda=460 \mathrm{~nm}){ }^{76,77}$ Similar ao g- $\mathrm{C}_{3} \mathrm{~N}_{4}$, outros semicondutores também absorvem no visível, tais como o $\mathrm{WO}_{3}$ e o $\mathrm{BiVO}_{4}$, mas o nível da $\mathrm{BC}$ do g- $\mathrm{C}_{3} \mathrm{~N}_{4}$ é significativamente mais negativo do que esses e vários outros semicondutores utilizados em fotocatálise. Essa característica faz com que os e- fotogerados na $\mathrm{BC}$ do $\mathrm{g}-\mathrm{C}_{3} \mathrm{~N}_{4}$ tenham alto potencial para reduzir vários tipos de moléculas, favorecendo diversas aplicações, incluindo a decomposição fotocatalítica da água, a redução de $\mathrm{CO}_{2}$ e a degradação de poluentes emergentes. ${ }^{77}$ Outra vantagem do g- $\mathrm{C}_{3} \mathrm{~N}_{4}$ está relacionada aos seus principais precursores de síntese, a melamina e ureia, que são materiais acessíveis e de baixo custo. Devido a essas características, o g- $\mathrm{C}_{3} \mathrm{~N}_{4}$ é frequentemente utilizado como um dos componentes de diversas heteroestruturas para aumentar a eficiência dos materiais sob irradiação visível. ${ }^{78}$ Kumar e colaboradores ${ }^{78}$ reportaram a síntese de $\mathrm{g}-\mathrm{C}_{3} \mathrm{~N}_{4} / \mathrm{SrTiO}_{3}$ pelo método dos precursores poliméricos e policondensação térmica da melamina. Os resultados demonstraram que as heteroestruturas apresentaram atividade fotocatalítica frente a degradação da rodamina B sob irradiação visível.

Zhang e colaboradores ${ }^{79}$ reportaram a fabricação de materiais de $\mathrm{g}-\mathrm{C}_{3} \mathrm{~N}_{4} /$ óxido de grafeno com elevada capacidade adsorvente e fotocatalítica. $\mathrm{O} g-\mathrm{C}_{3} \mathrm{~N}_{4}$ foi dispersado uniformemente sobre o óxido de grafeno, proporcionando grande absorção da luz incidente, excelente interação com a molécula poluente e melhor separação das cargas fotogeradas $\mathrm{e}^{-} / \mathrm{h}^{+}$. Wang e colaboradores ${ }^{80}$ apresentaram a obtenção de compósitos de g- $\mathrm{C}_{3} \mathrm{~N}_{4} / \mathrm{Nb}_{2} \mathrm{O}_{5}$ com fotoatividade aumentada sob luz visível. $\mathrm{Na}$ mesma linha, $\mathrm{Xu}$ e colaboradores ${ }^{81}$ apresentaram a síntese de fotocatalisadores heteroestruturados de $\mathrm{CdS} @ \mathrm{C}_{3} \mathrm{~N}_{4}$ do tipo core-shell com elevada atividade e Wang e colaboradores ${ }^{82}$ também estudaram a síntese de heteroestruturas de $\mathrm{g}-\mathrm{C}_{3} \mathrm{~N}_{4} / \mathrm{BiVO}_{4}$ com atividade fotocatalítica aumentada em relação aos componentes puros sob irradiação visível.

É importante destacar que, apesar dos avanços na obtenção de bons fotocatalisadores, especialmente quando se usa semicondutores heteroestruturados, a aplicação da fotocatálise heterogênea em sistemas reais de tratamento de efluentes ainda é limitada. Além da escolha de um fotocatalisador adequado, existem vários outros fatores a serem considerados para o projeto de um sistema reacional. Entre as variáveis de processo que influenciam na eficiência da fotocatálise estão o pH, a temperatura, a dispersão da radiação, a concentração do $\mathrm{O}_{2}$ e do catalisador, além da concentração inicial do poluente. ${ }^{83} \mathrm{E}$ preciso definir também a forma como o fotocatalisador será utilizado, se em suspensão aquosa ou imobilizado em um substrato rígido. A primeira permite maiores taxas de degradação, porém demanda uma etapa adicional de separação, como filtração ou centrifugação, aumentando a complexidade e os custos do processo. ${ }^{84}$

\section{Remoção de metais pesados}

Alguns íons de metais pesados podem ser encontrados em águas residuais, tais como os íons dos elementos cromo $(\mathrm{Cr})$, mercúrio $(\mathrm{Hg})$, chumbo $(\mathrm{Pb})$, cádmio $(\mathrm{Cd})$, e arsênio (As) ${ }^{85,86} \mathrm{~A}$ alta toxicidade e os impactos ambientais causados por esses metais pesados têm motivado o desenvolvimento de processos tecnológicos para a remoção desses poluentes de efluentes aquosos de diferentes matrizes.

O Cr (VI), por exemplo, é amplamente utilizado nos diversos processos industriais, como galvanoplastia e curtimento de couro, que são conhecidos por gerarem grandes quantidades de efluentes. No entanto, essa espécie é altamente tóxica e possui efeitos mutagênico e carcinogênico em organismos vivos. ${ }^{87} \mathrm{O} \mathrm{Cr}$ (VI) é tipicamente encontrado como espécie aniônica $\mathrm{Cr}_{2} \mathrm{O}_{7}{ }^{2-}$ ou $\mathrm{CrO}_{4}{ }^{2-}$, que são estáveis em solução aquosa e não precipitam com o aumento do $\mathrm{pH} .{ }^{88}$ Nesse caso, os efluentes contendo $\mathrm{Cr}$ (VI) podem ser submetidos a um processo de redução para obter $\mathrm{Cr}$ (III) para ser posteriormente precipitado. ${ }^{89}$ Além disso, o cromo trivalente ( $\mathrm{Cr}$ (III)) tem baixa toxicidade e é um nutriente essencial para o corpo humano em pequenas quantidades. ${ }^{90}$

Nesse sentido, a fotorredução de Cr (VI) utilizando semicondutores é uma alternativa mais econômica e sustentável com relação aos processos convencionais de tratamento de cromo que usam, por exemplo, agentes redutores em meios ácido, pois não gera resíduos secundários e poderia utilizar radiação solar como fonte de energia. ${ }^{91} \mathrm{O}$ processo de fotorredução de $\mathrm{Cr}(\mathrm{VI})$ pode ser resumido pelas seguintes equações quando o $\mathrm{TiO}_{2}$ é aplicado no processo, no qual as cargas fotogeradas atuam oxidando a água e reduzindo o ânion $\mathrm{HCrO}_{4}{ }^{-92,93}$

$$
\begin{gathered}
\mathrm{TiO}_{2}+h v \leftrightarrow \mathrm{TiO}_{2}\left(e_{\mathrm{CB}}^{-}+h^{+}{ }_{\mathrm{VB}}\right) \\
2 \mathrm{H}_{2} \mathrm{O}+4 \mathrm{TiO}_{2}\left(h^{+}{ }_{\mathrm{vB}}\right) \leftrightarrow \mathrm{O}_{2}+4 \mathrm{H}^{+}+4 \mathrm{TiO}_{2} \\
\mathrm{HCrO}_{4}^{-}+7 \mathrm{H}^{+}+3 e^{-} \leftrightarrow \mathrm{Cr}^{3+}+4 \mathrm{H}_{2} \mathrm{O}
\end{gathered}
$$

Diferentes heteroestruturas têm sido estudadas com o objetivo de aumentar o desempenho desse processo. Por exemplo, no estudo de Nogueira e colaboradores ${ }^{94}$ foi verificado que a deposição de $\mathrm{CuO}$ sobre a estrutura pré-formada do $\mathrm{Nb}_{2} \mathrm{O}_{5}$ conduziu a uma diminuição do valor de band gap das heteroestruturas, tornando o processo de fotorredução do $\mathrm{Cr}$ (VI) a Cr (III) mais eficiente sob irradiação visível. Além disso, as heterojunções formadas facilitaram a transferência de cargas, reduzindo a recombinação dos portadores de carga. A heteroestrutura de $\mathrm{Nb}_{2} \mathrm{O}_{5} / \mathrm{CuO}$ exibiu atividade fotocatalítica aproximadamente 20 vezes maior que a dos semicondutores puros.

Como já mencionado nos processos foto-oxidativos, o g- $\mathrm{C}_{3} \mathrm{~N}_{4}$ destaca-se para aplicação em processos de fotorredução, pois exibe a $\mathrm{BC}$ com potencial extremamente redutor, i.e. $-1,3 \mathrm{~V}$ vs $\mathrm{EPH}$, favorecendo a redução de diversas espécies a partir dos e- fotogerados na sua BC. No entanto, esse semicondutor apresenta uma recombinação rápida dos portadores de carga, o que diminui drasticamente a sua atividade fotocatalítica na redução de $\mathrm{Cr}$ (VI). ${ }^{95}$ Além do g- $\mathrm{C}_{3} \mathrm{~N}_{4}$, outros materiais carbonáceos, tais como nanotubos de carbono, carvão ativado, grafeno apresentam propriedades eletrônicas 
interessantes, mas baixa atividade quando utilizados puros por diferentes motivos. Desta forma, a formação de heterojunções com esses materiais é uma estratégia eficiente para melhorar suas atividades fotocatalíticas pelo aumento da separação efetiva dos pares $\mathrm{e}^{-/ h^{+}}$e melhorar a resposta de materiais com elevado $E_{\mathrm{g}}$ na faixa de luz visível. ${ }^{96-98}$

A presença de arsênio nas águas residuais é também uma grande preocupação de saúde pública em todo o mundo. O arsênico é um nutriente essencial em baixas concentrações; no entanto, sua ingestão prolongada em níveis elevados pode provocar problemas de saúde, tais como câncer, doenças cardiovasculares e neurológicas. Nesse sentido, o desenvolvimento de tecnologias para a remoção de arsênio de águas residuais, nas quais a concentração de metais excede aos limites determinados pela Organização Mundial de Saúde, é também atualmente uma importante reivindicação. ${ }^{99}$

O arsênio está presente em meio aquoso como As (III) e As (V), sendo o primeiro mais tóxico e mais difícil de ser removido da água pela maioria dos métodos de tratamento. ${ }^{99,100} \mathrm{O}$ As (III) é tipicamente oxidado a As (V) e posteriormente removido por adsorção, precipitação, troca iônica e outras técnicas. Essa reação pode ser realizada também pelo uso de processos fotocatalíticos, nos quais os radicais hidroxila formados são os agentes oxidantes. Nesse sentido, Arabnezhad e colaboradores aplicaram heteroestruturas de $\mathrm{TiO}_{2} / \mathrm{ZnO}$ sintetizadas com diferentes razões $\mathrm{Ti} / \mathrm{Zn}$ à foto-oxidação de As (III). As heteroestruturas apresentaram excelente desempenho sob exposição à radiação visível e ultravioleta devido à presença das heterojunções entre os óxidos, sendo que os radicais hidroxila foram as principais espécies ativas no processo. ${ }^{100}$

A fotocatálise heterogênea utilizando-se heteroestruturas de semicondutores aplicada à remoção de metais pesados apresenta como principal vantagem em relação a outros processos físíco-químicos (precipitação química, adsorção, filtração e eletrodiálise) a possibilidade de oxidar simultaneamente poluentes orgânicos. Essa vantagem é muito importante, pois elimina a necessidade de utilização de um tratamento prévio do efluente para remover os poluentes orgânicos, como ocorre nesses processos convencionais de remoção de metais, proporcionando um menor custo operacional. Por outro lado, a fotocatálise requer um longo tempo de operação para remover os metais pesados, necessitando ainda estudos adicionais para superar esse desafio. 85

\section{Inativação de microorganismos patogênicos}

Os microrganismos patogênicos são outro tipo de contaminante muito frequente em efluentes líquidos, principalmente em efluentes domésticos. Tradicionalmente, a eliminação desses microorganismos é feita através do uso de agentes químicos como o ozônio e o cloro. No entanto, muitos patógenos emergentes apresentam rápida evolução e alta capacidade de adaptação para resistirem a esse processo. ${ }^{101}$ Além disso, esse método tende a gerar subprodutos tóxicos. ${ }^{102}$ Nesse contexto, novas tecnologias para a desinfecção vêm sendo estudadas, incluindo a fotocatálise heterogênea. Desde que Matsunaga e colaboradores ${ }^{103}$ reportaram em 1985 a inativação bacteriana através da fotocatálise com o $\mathrm{TiO}_{2}$, vários outros trabalhos demostraram a eficácia da fotocatálise heterogênea na inativação de bactérias e de outros tipos de microorganismos, como vírus, protozoários e fungos. ${ }^{104} \mathrm{O}$ mecanismo da inativação fotocatalítica varia de acordo com as características de cada microorganismo. Porém, é consenso entre os pesquisadores que os radicais gerados após a irradiação do semicondutor são as espécies responsáveis pelo início do processo de morte celular. ${ }^{105} \mathrm{Na}$ inativação de bactérias, por exemplo, os radicais hidroxila desempenham um papel fundamental, afetando primeiramente a membrana fosfolipídica da parede celular e induzindo danos celulares através de um rápido vazamento de íons. ${ }^{102}$
O semicondutor mais estudado na desinfecção microbiana também é o $\mathrm{TiO}_{2} \cdot{ }^{106}$ Contudo, alguns fatores, tais como sua baixa atividade fotocatalítica sob luz solar, alta taxa de recombinação e dificuldade de separação e reúso, têm motivado o desenvolvimento de fotocalisadores heteroestruturados. Nesse contexto, heteroestruras à base de $\mathrm{TiO}_{2}$, tais como $\mathrm{TiO}_{2} / \mathrm{Bi}_{2} \mathrm{WO}_{6}{ }^{107} \mathrm{TiO}_{2} / \mathrm{g}-\mathrm{C}_{3} \mathrm{~N}_{4}{ }^{108} \mathrm{e} \mathrm{Ag} /$ $\mathrm{TiO}_{2}{ }^{109}$ vêm ganhando destaque em processos de desinfecção. Wang e colaboradores, ${ }^{110}$ por exemplo, desenvolveram um fotocalisador associando o óxido de grafeno $(\mathrm{GO})$ ao $\mathrm{TiO}_{2}$ através de uma mistura ultrassônica. A atividade fotocatalítica do $\mathrm{TiO}_{2} / \mathrm{GO}$ se mostrou superior frente aos materiais puros na inativação da bactéria Escherichia coli sob irradiação solar. Além disso, os resultados mostraram também um comportamento acelerado de sedimentação para o $\mathrm{TiO}_{2} / \mathrm{GO}$, favorecendo sua separação do meio reacional.

A associação de um semicondutor com propriedades magnéticas como, por exemplo, a magnetita $\left(\mathrm{Fe}_{3} \mathrm{O}_{4}\right)$ ao $\mathrm{TiO}_{2}$ também é uma estratégia interessante para facilitar a separação do fotocatalisador no final do processo, resultando em um menor custo operacional em comparação a outros métodos de separação como a centrifugação e filtração. ${ }^{111}$ Nesse sentido, Ma e colaboradores ${ }^{111}$ reportaram a síntese de $\mathrm{Fe}_{3} \mathrm{O}_{4} / \mathrm{TiO}_{2}$ com elevada atividade fotocatalítica na inativação das bactérias Escherichia coli e Staphylococcus aureus, com a heteroestrutura apresentando resultados superiores em relação aos componentes puros. Segundo os autores, a associação do $\mathrm{Fe}_{3} \mathrm{O}_{4}$ com o $\mathrm{TiO}_{2}$ foi fundamental para a supressão da recombinação das cargas e também para a ativação do material na faixa do visível. Os experimentos de recuperação e reutilização mostraram ainda que a eficiência de desinfecção do $\mathrm{Fe}_{3} \mathrm{O}_{4} / \mathrm{TiO}_{2}$ se manteve elevada após cinco ciclos de operação.

Heteroestruturas de semicondutores à base de bismuto também têm sido consideradas promissoras para a inativação de microorgânismos. ${ }^{12,113}$ Nesse sentido, Xiang e colaboradores ${ }^{114}$ sintetizaram heteroestruturas do tipo p-n de $\mathrm{BiOI} / \mathrm{BiVO}_{4}$ por um método de coprecipitação. Tais heteroestruturas apresentaram estabilidade e atividade fotocatalíticas melhoradas na inativação de bactérias da espécie Pseudomonas auruginosa sob irradiação visível. Estudos do mecanismo de inativação mostraram que os radicais ${ }^{\circ} \mathrm{OH}$ e os $\mathrm{h}^{+}$na $\mathrm{BV}$ do BiOI foram as principais espécies reativas.

Diante dos excelentes resultados experimentais, fica evidente que a fotocatálise heterogênea é uma tecnologia promissora também para a desinfecção da água. Entretanto, é preciso ressaltar que as respostas das bactérias ao tratamento fotocatalítico em amostras reais de água diferem consideravelmente daquelas em amostras de água em testes laboratoriais. ${ }^{114}$ Acredita-se que tratamentos preliminares podem ser necessários, pois a presença de íons inorgânicos dissolvidos em sólidos suspensos e compostos orgânicos (principalmente substâncias húmicas) tem influência na eficiência do tratamento. ${ }^{107}$ Assim, para viabilizar essa tecnologia é fundamental a busca constante por melhores fotocalisadores, visando principalmente um melhor aproveitamento da luz solar. Além disso, a melhoria no projeto dos reatores assim como a avaliação da longevidade do fotocatalisador sob condições reais de operação são essenciais. ${ }^{104}$ Outro desafio é a elucidação do mecanismo de desinfecção para certos microorganismos, como fungos e protozoários, que ainda não está esclarecido. ${ }^{102}$

\section{Abatimento de poluentes em fase gasosa}

Outro grande desafio da área ambiental diz respeito ao desenvolvimento de técnicas eficientes para a remoção de poluentes gasosos, tais como, os compostos orgânicos voláteis (COVs), os óxidos de nitrogênio $\left(\mathrm{NO}_{\mathrm{x}}\right)$, os óxidos de enxofre $\left(\mathrm{SO}_{\mathrm{x}}\right)$ e os óxidos de carbono $\left(\mathrm{CO}\right.$ e $\left.\mathrm{CO}_{2}\right)$. O abatimento fotocatalítico de tais compostos utilizando um semicondutor como catalisador tem sido proposto como um 
processo alternativo e promissor devido principalmente ao seu baixo custo operacional e à sua alta eficiência. Assim como no tratamento de águas poluídas via fotocatálise heterogênea, os sistemas heteroestruturados vêm sendo desenvolvidos para a aplicação como fotocatalisadores em sistemas sólido - gás devido ao significativo aumento na eficiência catalítica - quando comparados aos componentes isolados - e por ampliar a faixa de absorção do espectro eletromagnético. A seguir serão apresentados alguns trabalhos que mostram os avanços científicos alcançados até o momento e os principais desafios que ainda precisam ser solucionados nessa área.

\section{Foto-oxidação de compostos orgânicos voláteis (COVs)}

Os compostos orgânicos voláteis (COVs) são um grupo de compostos contendo carbono que evaporam prontamente à temperatura ambiente e à pressão atmosférica. $\mathrm{O}$ tricloroetano, o tricloroetileno, o formaldeido e os hidrocarbonetos BTEX (benzeno, tolueno, etilbenzeno, xilenos) são exemplos de COVs que podem causar graves danos ao meio ambiente e a saúde humana. Esses poluentes são tipicamente originários de complexos petroquímicos, usinas de energia, emissões veiculares, entre outros. Os COVs têm efeitos severos a longo prazo nos seres humanos, sendo considerados carcinogênicos, mutagênicos ou teratogênicos. ${ }^{115}$ Em termos ambientais, alguns COVs podem contribuir para a formação do smog fotoquímico e ozônio $\left(\mathrm{O}_{3}\right)$ troposférico, assim como a depleção do ozônio estratosférico e o aumento do efeito estufa. ${ }^{116}$

A oxidação térmica, a adsorção utilizando materiais porosos com elevada área superficial, tais como carvão ativado e zeólita, e a biofiltração são tecnologias comumente empregadas no tratamento de efluentes gasosos contendo COVs. Entretanto, há várias desvantagens na utilização desses processos convencionais, tais como: (i) o elevado custo energético na oxidação térmica devido ao uso de temperaturas que variam entre 200 e $1200{ }^{\circ} \mathrm{C}$ dependendo do tipo de COV; (ii) a característica não destrutiva do processo de adsorção, produzindo assim um resíduo secundário sólido; e (iii) a baixa eficiência da biofiltração na degradação de altas concentrações de COVs. ${ }^{116}$ Nesse contexto, a oxidação fotocatalítica surge como uma tecnologia alternativa eficiente e de baixo custo para o tratamento dos COVs, sendo atualmente um importante foco de pesquisa. A oxidação dos COVs via fotocatálise heterogênea segue basicamente os mesmos mecanismos de reação da oxidação de compostos orgânicos em meio aquoso. Isso significa que podem ocorrer pela interação direta da molécula poluente com os sítios ativos na superfície do fotocatalisador, onde ocorrem as transferências eletrônicas que induzem processos de oxidação e redução (reação direta), ou pela formação de espécies reativas, tais como os radicais ${ }^{\circ} \mathrm{OH}$ e $\mathrm{O}_{2}{ }^{--}$, pela reação entre água adsorvida, hidroxilas superficiais ou oxigênio molecular e os pares $\mathrm{e}^{-} / \mathrm{h}^{+}$fotogerados (reação indireta). Diversos semicondutores, tais como, $\mathrm{TiO}_{2}, \mathrm{ZnO}$, e $\mathrm{Nb}_{2} \mathrm{O}_{5}$, quando utilizados de forma isolada, apresentam elevada fotoatividade na oxidação de um grande número de COVs. ${ }^{115,117,118}$ Entretanto, o desenvolvimento de fotocatalisadores heteroestruturados tem possibilitado alcançar melhores performances com relação ao processo de mineralização da molécula poluente a $\mathrm{CO}_{2}, \mathrm{H}_{2} \mathrm{O}$ e ácidos inorgânicos, e em termos cinéticos, em função da redução da recombinação das cargas fotogeradas $\left(\mathrm{e}^{-} / \mathrm{h}^{+}\right)$. Além disso, viabilizam o uso da luz solar como fonte de energia pela utilização de, pelo menos, um semiconductor com energia de band gap na faixa do visível, tornando o processo mais sustentável. Nesse sentido, diferentes configurações baseadas na junção de dois ou mais semicondutores têm sido propostas para obter fotocatalisadores cada vez mais eficientes na oxidação de diferentes tipos de COVs.

Xin e colaboradores, ${ }^{119}$ por exemplo, desenvolveram um fotocatalisador com múltiplas junções com o objetivo principal de aumentar o desempenho fotocatalítico do $\mathrm{TiO}_{2}$ sob luz solar pela combinação com os semicondutores $\mathrm{CuS}\left(\mathrm{E}_{\mathrm{g}}=2,2 \mathrm{eV}\right)$ e $\mathrm{CdS}$ $\left(\mathrm{E}_{\mathrm{g}}=2,4 \mathrm{eV}\right)$ frente a degradação de tolueno gasoso. Os resultados revelaram que, devido à melhor separação de cargas e ampliação da banda de absorção, a heteroestrutura $\mathrm{CuS}-\mathrm{CdS} / \mathrm{TiO}_{2}$ foi significativamente mais fotoativa que o $\mathrm{TiO}_{2}$ puro e também mais fotoativa que as heteroestruturas binárias $\mathrm{CuS} / \mathrm{TiO}_{2}$ e $\mathrm{CdS} / \mathrm{TiO}_{2}$, em ensaios ativados por luz solar artificial. Além disso, os autores também compararam a atividade das heteroestruturas $\mathrm{CdS} / \mathrm{TiO}_{2}$ e $\mathrm{CuS}-\mathrm{CdS} / \mathrm{TiO}_{2}$ após 4 ciclos de reação e observaram uma maior estabilidade fotocatalítica para o sistema ternário, característica fundamental para aplicação em larga escala. Entretanto, os autores salientam que apesar de obterem aproximadamente $88 \%$ de conversão de tolueno após 100 min de iluminação, apenas aproximadamente $32 \%$ correspondem à mineralização da molécula alvo a $\mathrm{CO}_{2}$ e $\mathrm{H}_{2} \mathrm{O}$, sugerindo que intermediários orgânicos indesejáveis podem ter sido gerados.

Em um trabalho semelhante, Ji e colaboradores ${ }^{120}$ desenvolveram outra heteroestrutura com arquitetura ternária com multiplas junções, sendo constituida por titanato de estrôncio, $\mathrm{SrTiO}_{3}$ (STO), suportado em nanotubos de $\mathrm{TiO}_{2}(\mathrm{TN})$ e sensibilizado por g- $\mathrm{C}_{3} \mathrm{~N}_{4}(\mathrm{CN})$. Eles estudaram inicialmente a atividade fotocatalítica da heteroestrutura STO/TN sob irradiação UV na oxidação de tolueno gasoso, sendo mais eficiente que TN, STO e P25 comercial e atingindo completa mineralização em 4,5 h. Sob irradiação visível, a heteroestrutura ternária $\mathrm{CN}-\mathrm{STO} / \mathrm{TN}$ apresentou uma eficiência fotocatalítica substancialmente maior que os seus componentes puros (TN, STO e CN) na mineralização de tolueno ( 93\% em 6 h) e o P25 comercial. Segundo os autores, essa arquitetura com multiplas junções promove um efeito sinérgico na geração das cargas fotoinduzidas, tanto sob iluminação UV quanto visível, e também no seu transporte e separação.

Outros trabalhos desenvolveram de maneira semelhante heteroestruturas binárias e ternárias com desempenhos fotocatalíticos superiores aos seus componentes puros frente à oxidação de $\mathrm{COV}$, como Sun e colaboradores com $\mathrm{V}_{2} \mathrm{O}_{5} / \mathrm{BiVO}_{4} / \mathrm{TiO}_{2}$ na oxidação de tolueno, ${ }^{121}$ Katsumata e colaboradores ${ }^{122}$ com g- $\mathrm{C}_{3} \mathrm{~N}_{4} / \mathrm{WO}_{3}$ na oxidação de acetaldeido, Zou e colaboradores ${ }^{123}$ com $\mathrm{BiPO}_{4} / \mathrm{BiOBr}$ na oxidação de o-diclorobenzeno.

Por fim, o desenvolvimento de novos fotocatalisadores pela combinação de diferentes semicondutores possibilita melhorar o processo fotocatalítico de mineralização de COVs pela diminuição das taxas de recombinação dos pares $\mathrm{e}^{-} / \mathrm{h}^{+}$, assim como pela ativação sob irradiação visível e diminuição da fotocorrosão. Entretanto, é importante ressaltar que o estudo e o controle dos parâmetros operacionais, tais como, umidade, temperatura, concentração de oxigênio, concentração e tempo de residência do poluente, presença de interferentes, tipo e intensidade da radiação, além do tipo de reator, são fundamentais para o estabelecimento de um sistema fotocatalítico de controle de emissão de COVs eficiente. ${ }^{124}$

\section{Abatimento fotocatalítico de $\mathrm{NO}_{x}$}

$\mathrm{O}$ termo $\mathrm{NO}_{\mathrm{x}}$ está associado principalmente ao óxido nítrico (NO), dióxido de nitrogênio $\left(\mathrm{NO}_{2}\right)$ e óxido nitroso $\left(\mathrm{N}_{2} \mathrm{O}\right)$, que são produzidos naturalmente através de muitas fontes associadas ao ciclo do nitrogênio, ou por atividades humanas, tais como agricultura, queima de combustíveis fósseis, incineração de resíduos domésticos e industriais e alguns processos industriais. $\mathrm{O}$ abatimento dos óxidos de nitrogênio $\left(\mathrm{NO}_{\mathrm{x}}\right)$ é um assunto de grande importância, visto que esses compostos contribuem para a poluição atmosférica e para a baixa qualidade do ar. Especificamente, as emissões dos óxidos de nitrogênio contribuem fortemente para o surgimento de graves fenômenos da poluição ambiental, tais como, a chuva ácida, o smog fotoquímico, a formação de ozônio $\left(\mathrm{O}_{3}\right)$ troposférico, assim como a depleção de sua camada na estratosfera. ${ }^{125,126}$ 
Processos catalíticos clássicos permitem o abatimento dos óxidos de nitrogênio pela redução a nitrogênio molecular na presença ou não de agentes redutores, tais como hidrogênio molecular $\left(\mathrm{H}_{2}\right)$, monóxido de carbono (CO), amônia $\left(\mathrm{NH}_{3}\right)$, entre outros. Entretanto, o sucesso desses processos está ainda associado a um elevado custo energético, uma vez que se faz necessário o uso de temperaturas elevadas para que as reações ocorram com conversões satisfatórias. ${ }^{127}$ Diante desse problema, diversos grupos de pesquisa têm proposto o abatimento fotocatalítico de tais compostos como um processo alternativo e promissor devido principalmente ao seu menor custo operacional, uma vez que se pode utilizar a luz solar como fonte de energia, e à sua alta eficiência. $\mathrm{O}$ abatimento fotocatalítico de $\mathrm{NO}_{x}$ pode seguir um mecanismo de oxidação a ácido nítrico $\left(\mathrm{NO}_{x} \rightarrow \mathrm{HNO}_{2} \rightarrow \mathrm{NO}_{2} \rightarrow \mathrm{HNO}_{3}\right.$ ) ou de redução a nitrogênio molecular $\left(\mathrm{NO}_{\mathrm{x}} \rightarrow \mathrm{N}_{2}+\mathrm{O}_{2}\right)$. De acordo com Bowering e colaboradores, ${ }^{128} \mathrm{o}$ mecanismo de foto-redução de $\mathrm{NO}_{\mathrm{x}}$ pode ser descrito conforme as equações abaixo:

$$
\begin{gathered}
\mathrm{NO}_{\mathrm{ads}} \rightarrow \mathrm{N}_{\mathrm{ads}}+\mathrm{O}_{\mathrm{ads}} \\
\mathrm{NO}_{\mathrm{ads}}+\mathrm{N}_{\mathrm{ads}} \rightarrow \mathrm{N}_{2} \mathrm{O}_{\mathrm{ads}} \\
\mathrm{NO}_{\mathrm{ads}}+\mathrm{O}_{\mathrm{ads}} \rightarrow \mathrm{NO}_{2, \text { ads }} \\
2 \mathrm{O}_{\mathrm{ads}} \rightarrow \mathrm{O}_{2, \text { ads }} \\
2 \mathrm{~N}_{\mathrm{ads}} \rightarrow \mathrm{N}_{2, \text { ads }} \\
2 \mathrm{NO}_{\mathrm{ads}} \rightarrow \mathrm{O}_{2, \text { ads }}+\mathrm{N}_{2, \text { ads }} \\
2 \mathrm{~N}_{2} \mathrm{O}_{\mathrm{ads}} \rightarrow \mathrm{O}_{2, \text { ads }}+2 \mathrm{~N}_{2, \mathrm{ads}}
\end{gathered}
$$

Como ilustrado na equação $7, \mathrm{o} \mathrm{NO}_{\mathrm{ads}}$ adsorvido na superfície do $\mathrm{TiO}_{2}$ fotoativado (equação (4)) irá receber o e- no seu orbital antiligante o que promove a quebra da ligação formando $\mathrm{N}_{\text {ads }}$ e $\mathrm{O}_{\text {ads }}$. Embora a fotorredução de $\mathrm{NO}_{x}$ a $\mathrm{N}_{2}$ seja uma tecnologia muito interessante e promissora, principalmente quando se utiliza outros poluentes gasosos associados ao processo como agentes redutores, como o $\mathrm{CO}$, hidrocarbonetos (e.g., $\mathrm{CH}_{4}$ ) ou $\mathrm{NH}_{3}$, a maioria dos estudos sobre abatimento fotocatalítico de $\mathrm{NO}_{\mathrm{x}}$ utilizando fotocatalisadores heteroestruturados encontrados na literatura refere-se à conversão de $\mathrm{NO}$ em $\mathrm{NO}_{3}{ }^{-}$ou $\mathrm{HNO}_{3}{ }^{127,129,130} \mathrm{O}$ mecanismo da foto-oxidação de $\mathrm{NO}_{x}$ pode ser descrito conforme as equações a seguir. ${ }^{130,131}$

$$
\begin{gathered}
\mathrm{NO}+{ }^{\circ} \mathrm{OH}_{\text {ads }} \rightarrow \mathrm{HNO}_{2} \\
\mathrm{HNO}_{2}+{ }^{\circ} \mathrm{OH}_{\text {ads }} \rightarrow \mathrm{NO}_{2}+\mathrm{H}_{2} \mathrm{O} \\
\mathrm{NO}_{2}+{ }^{\circ} \mathrm{OH}_{\text {ads }} \rightarrow \mathrm{HNO}_{3} \\
\mathrm{NO}+{ }^{\circ} \mathrm{O}_{2, \text { ads }}^{-} \rightarrow \mathrm{NO}_{3}^{-} \\
2 \mathrm{NO}+{ }^{-} \mathrm{O}_{2, \text { ads }}^{-} \rightarrow 2 \mathrm{NO}_{2}+\mathrm{e}^{-} \\
3 \mathrm{NO}_{2}+2 \mathrm{OH}^{-} \rightarrow 2 \mathrm{NO}_{3}^{-}+\mathrm{NO}+\mathrm{H}_{2} \mathrm{O}
\end{gathered}
$$

Ma e colaboradores ${ }^{132}$ reportaram uma heteroestrutura formada por g- $\mathrm{C}_{3} \mathrm{~N}_{4}$ e $\mathrm{TiO}_{2}$ comercial (P25) com um desempenho superior aos seus componentes isolados na foto-oxidação de NO sob irradiação UV e visível. Nesse estudo, foram analisadas diferentes proporções mássicas de $\mathrm{g}-\mathrm{C}_{3} \mathrm{~N}_{4}$ e no teor ótimo $\left(\sim 15 \%\right.$ de $\left.\mathrm{g}-\mathrm{C}_{3} \mathrm{~N}_{4}\right)$, a conversão de NO foi de $27 \%$, sendo maior que a do P25 puro (17\%) e g- $\mathrm{C}_{3} \mathrm{~N}_{4}$ puro $(7 \%)$ sob irradiação visível. A atividade da heteroestrutura de g- $\mathrm{C}_{3} \mathrm{~N}_{4} / \mathrm{TiO}_{2}$ também foi melhorada sob irradiação UV. Os autores atribuiram o aumento da atividade fotocatalítica à formação de heterojunções efetivas entre os semicondutores durante a síntese de g- $\mathrm{C}_{3} \mathrm{~N}_{4}$ na presença de $\mathrm{TiO}_{2}$ pré-formado. Além disso, os resultados indicaram que o radical ${ }^{\circ} \mathrm{O}_{2}{ }^{-}$foi a principal espécie ativa para oxidação de $\mathrm{NO}$ a $\mathrm{NO}_{3}^{-}$sob luz visível e UV.

Luévano-Hipólito e colaboradores ${ }^{133}$ também demonstraram a importância da otimização da relação quantitativa entre os componentes de uma determinada heteroestrutura para maximizar a atividade fotocatalítica. Eles investigaram a influência da porcentagem molar de $\mathrm{TiO}_{2}(5 \%, 15 \%, 50 \%, 70 \%, 80 \%$, e $87 \%)$ na heteroestrutura $\mathrm{WO}_{3} /$ $\mathrm{TiO}_{2}$ na oxidação fotocatalítica do NO sob irradiação UV e visível.
Os autores observaram que a eficiência fotocatalítica do $\mathrm{WO}_{3} / \mathrm{TiO}_{2}$ melhora com o aumento da quantidade de $\mathrm{TiO}_{2}$ superficial de $5 \%$ a $80 \%$, devido a uma melhor separação dos pares $\mathrm{e}^{-} / \mathrm{h}^{+}$fotogerados, como resultado da formação de junções efetivas entre os componentes da heteroestrutura. Outro estudo interessante na aplicação de fotocatalisadores heteroestruturados a base de $\mathrm{TiO}_{2}$ para a oxidação de $\mathrm{NO}_{\mathrm{x}}$ foi reportado por Tran e colaboradores, ${ }^{134}$ no qual mostram que a heteroestrutra $\mathrm{SnO}_{2}$ /nanotubos de $\mathrm{TiO}_{2}$ exibe desempenho fotocatalítico superior aos componentes puros e a mistura física entre eles, com eficiência de oxidação do NO de aproximadamente $60 \%$ sob irradiação visível e com efetiva inibição da produção de $\mathrm{NO}_{2}$, produto com elevada toxicidade comumente formado nesse tipo de reação. Os autores também justificaram os melhores resultados fotocatalíticos pela menor taxa de recombinação dos pares e- $/ \mathrm{h}^{+}$devido à formação de heterojunções entre os componentes da heteroestrutura, sendo observado também que os radicais $\mathrm{O}_{2}{ }^{-}$e ${ }^{\bullet} \mathrm{OH}$ desempenharam um papel predominante no processo de oxidação do NO.

Diversos grupos de pesquisa têm reportado a construção de arquiteturas heteroestruturadas com elevada eficiência na foto-oxidação de $\mathrm{NO}_{\mathrm{x}}$ envolvendo outros semicondutores, tais como, Man e colaboradores ${ }^{131}$ com g- $\mathrm{C}_{3} \mathrm{~N}_{4} @ \mathrm{Ag} / \mathrm{BiVO}_{4}$, Liu e colaboradores ${ }^{135} \mathrm{com}$ $\mathrm{AgVO}_{3}-\mathrm{g}_{-} \mathrm{C}_{3} \mathrm{~N}_{4}$, Wan e colaboradores ${ }^{136}$ com $\mathrm{BiVO}_{4} / \mathrm{CaIn}_{2} \mathrm{~S}_{4}$, Wan e colaboradores ${ }^{137}$ com $\mathrm{Bi}_{2} \mathrm{MoO}_{6} / \mathrm{ZnIn}_{2} \mathrm{~S}_{4}$, Zhang e colaboradores ${ }^{138}$ com $\mathrm{LaFeO}_{3}-\mathrm{SrTiO}_{3}$.

Por fim, é importante destacar que um dos principais desafios no abatimento de $\mathrm{NO}_{x}$ e outros gases poluentes via fotocatalise heterogênea é obter um fotocatalisador estável e ativo sob luz visível. Nesse sentido, o desenvolvimento de materiais heteroestruturados pode ser considerado como uma solução para tornar todo o processo mais eficaz e acessível, uma vez que pode possibitar a melhora das caracteristícas físicas, químicas e optoeletrônicas.

\section{Fotorredução do $\mathrm{CO}_{2}$ e produção de $\mathrm{H}_{2}$}

O desenvolvimento da redução fotocatalítica de $\mathrm{CO}_{2}$, também conhecida como fotossíntese artificial, visa solucionar a crescente demanda por energia e os problemas ambientais associados a queima de combustíveis fósseis. ${ }^{139}$ Esse processo permite transformar $\mathrm{CO}_{2}$ em combustíveis solares, principalmente hidrocarbonetos $\mathrm{C} 1, \mathrm{C} 2 \mathrm{e}$ C $3 .{ }^{140-143} \mathrm{O}$ acoplamento desse processo à dispositivos eletroquímicos permite também armazenar energia de fontes intermitentes/sazonais em energia química. Porém, vários desafios relacionados à baixa atividade, seletividade e estabilidade, e aos altos valores de band gap dos semicondutores ainda precisam ser superados para tornar esse processo viável do ponto de vista prático. A solução desses problemas está diretamente associada à otimização de procedimentos sintéticos e ao desenvolvimento de heteroestruturas, de modo a alcançar propriedades estruturais, eletrônicas, morfológicas e superficiais requeridas para essa aplicação.

Os principais produtos da redução fotocatalítica de $\mathrm{CO}_{2}$ e os potenciais de redução, representados pela $\mathrm{E}_{\text {Redução, são descritos a }}^{\circ}$ seguir: ${ }^{142,144}$

$\begin{array}{lc} & \mathrm{E}_{\text {redução }}^{\text {o }}(\mathrm{V}) \\ \mathrm{CO}_{2}+2 e^{-}+2 \mathrm{H}^{+} \rightarrow \mathrm{CO}+\mathrm{H}_{2} \mathrm{O} & -0.53 \\ \mathrm{CO}_{2}+2 e^{-}+2 \mathrm{H}^{+} \rightarrow \mathrm{HCOOH} & -0.61 \\ \mathrm{CO}_{2}+4 e^{-}+4 \mathrm{H}^{+} \rightarrow \mathrm{HCHO}+\mathrm{H}_{2} \mathrm{O} & -0.48 \\ \mathrm{CO}_{2}+6 e^{-}+6 \mathrm{H}^{+} \rightarrow \mathrm{CH}_{3} \mathrm{OH}+\mathrm{H}_{2} \mathrm{O} & -0.38 \\ \mathrm{CO}_{2}+8 e^{-}+8 \mathrm{H}^{+} \rightarrow \mathrm{CH}_{4}+2 \mathrm{H}_{2} \mathrm{O} & -0.24\end{array}$

A fotorredução de $\mathrm{CO}_{2}$ ocorre em diferentes etapas, que envolvem adsorção, ativação e dissociação da ligação carbono e oxigênio. A etapa de ativação é especialmente desafiadora, pois a molécula de 
$\mathrm{CO}_{2}$ é altamente estável e inerte. ${ }^{145}$ A competição com outras reações de redução, como a evolução de $\mathrm{H}_{2}$ do processo de water splitting que apresenta um potencial de redução menor, causa um sério desafio para controlar a seletividade do processo, e reduz significativamente a eficiência da fotorredução de $\mathrm{CO}_{2} \cdot{ }^{146} \mathrm{Uma}$ alternativa possível seria identificar um conjunto de óxidos que, quando combinados, apresentem uma superfície com alta afinidade pelo $\mathrm{CO}_{2}$ e, simultaneamente, apresentem propriedades eletrônicas adequadas (i.e., posições das bandas adequadas e maior tempo de vida dos portadores de carga) para reduzir o $\mathrm{CO}_{2}$ com eficiência e seletividade.

A fotorredução do $\mathrm{CO}_{2}$ envolve uma série de etapas reacionais e a troca de uma grande quantidade de $\mathrm{e}^{-}$, o que torna esse processo complexo e mais difícil de ser realizado que a evolução de $\mathrm{H}_{2}{ }^{147}$ Por exemplo, a fotorredução de $\mathrm{CO}_{2}$ para $\mathrm{CH}_{4}$ requer $8 \mathrm{e}$, enquanto a geração $\mathrm{H}_{2}$ requer apenas $2 \mathrm{e}^{-148} \mathrm{Na}$ primeira etapa, a molécula de $\mathrm{CO}_{2}$ é adsorvida à superfície do fotocatalisador e reage com e- para produzir radicais de dióxido de carbono $\left(\mathrm{CO}_{2}^{-}\right)$, que reagem ainda com íons $\mathrm{H}^{+}$para formar radicais ${ }^{\circ} \mathrm{CH}_{3}$ de superfície, produzindo ao fim $\mathrm{CH}_{4} \cdot{ }^{149}$

A fim de resolver as limitações cinéticas e termodinâmicas da fotorredução de $\mathrm{CO}_{2}$, os semicondutores devem apresentar uma eficiente separação de carga e boa afinidade ao $\mathrm{CO}_{2}$, de modo que a formação de $\mathrm{H}_{2}$ seja evitada enquanto as cargas se transferem para $\mathrm{CO}_{2}$. Alguns trabalhos têm demonstrado que materiais com superfície alcalina (e.g., $\mathrm{MgO}, \mathrm{CaO}, \mathrm{SrO}$ e $\mathrm{BaO}$ ) possuem uma interação com o $\mathrm{CO}_{2}$ mais forte do que superfícies ácidas, o que pode auxiliar na etapa de adsorção e ativação do $\mathrm{CO}_{2} \cdot{ }^{150,151}$ No entanto, o $\mathrm{MgO}$ apresenta um band gap na faixa de 4,5 a 5,0 eV, o que diminui a eficiência do processo fotocatalítico devido à pequena absorção da radiação. Portanto, uma heteroestrutura formada por $\mathrm{MgO}$, por exemplo, e outro semicondutor com energia de band gap adequada, pode fornecer simultaneamente uma boa interação com o $\mathrm{CO}_{2} \mathrm{e}$ propriedades eletrônicas que permitam um bom aproveitamento da radiação e eficiente separação das cargas.

Baseando-se nesse princípio, Li e colaboradores ${ }^{152}$ produziram filmes de nanotubos de $\mathrm{TiO}_{2} 1 \mathrm{D}$ com camadas finas de $\mathrm{MgO}$. Essa heteroestrutura exibiu uma alta eficiência na fotorredução de $\mathrm{CO}_{2}$ a $\mathrm{CH}_{4}$ em comparação com o filme de $\mathrm{TiO}_{2}$ puro. Os autores observaram que o $\mathrm{MgO}$ desempenha um papel fundamental na metanação do $\mathrm{CO}_{2}$, pois possui capacidade de adsorver fortemente o $\mathrm{CO}_{2}$, e forma carbonato de magnésio na superfície, sendo essa a etapa de ativação da molécula de $\mathrm{CO}_{2}$.

Xie e colaboradores ${ }^{153}$ estudaram a atividade de heteroestruturas de $\mathrm{Pt}-\mathrm{TiO}_{2}$ na fotorredução de $\mathrm{CO}_{2}$. Avaliaram ainda o efeito da adição de $\mathrm{MgO}$ no catalisador $\mathrm{Pt}-\mathrm{TiO}_{2}$ e observaram um aumento da seletividade da formação de $\mathrm{CH}_{4}$ e a supressão da formação de $\mathrm{H}_{2}$. Esses resultados foram atribuídos ao aumento da quimissorção de $\mathrm{CO}_{2}$ e à alta densidade eletrônica na superfície de $\mathrm{TiO}_{2}$ promovida pelo $\mathrm{MgO}$ e Pt. Outros pesquisadores mostraram resultados semelhantes pela formação de heteroestruturas entre um semicondutor (e.g., $\mathrm{TiO}_{2}$, g- $\mathrm{C}_{3} \mathrm{~N}_{4}$ ), co-catalisadores (e.g., $\mathrm{Ag}, \mathrm{Pt}$ ) e o $\mathrm{MgO} .{ }^{151}$

Para superar o desafio da adsorção e ativação da molécula de $\mathrm{CO}_{2}$ na superfície do semicondutor, alguns autores têm também preparado semicondutores pela deposição de bases $(\mathrm{NaOH}$ e $\mathrm{KOH})$ nas suas superfícies. Foi observado que a deposição de $\mathrm{KOH}$ sobre $\mathrm{g}-\mathrm{C}_{3} \mathrm{~N}_{4}$ resultou no aumento da produção de $\mathrm{CO}, \mathrm{CH}_{4} \mathrm{e} \mathrm{CH}_{3} \mathrm{CHO}$ em 3 vezes. Os autores atribuíram essa melhora à formação de um intermediário de carbonato devido à presença do cátion metálico $\mathrm{K}^{+} .{ }^{154}$

Wang e colaboradores ${ }^{155}$ demonstraram que quando a fotorredução de $\mathrm{CO}_{2}$ é realizada com as heteroestruturas $\mathrm{CdSe} / \mathrm{Pt} / \mathrm{TiO}_{2}$, a velocidade de formação do $\mathrm{CH}_{4}$ é de aproximadamente $48 \mathrm{mg} \cdot \mathrm{g}$ ${ }^{-1} \cdot \mathrm{h}^{-1}$, quantidades traços de $\mathrm{H}_{2}$. Quando a Pt é substituída por $\mathrm{Fe}$, a seletividade da fotorredução é direcionada para a geração de $\mathrm{H}_{2}$, alcançando valores superiores a $55 \mathrm{mg} \cdot \mathrm{g}^{-1} \cdot \mathrm{h}^{-1}$, mostrando assim que o tipo de heteroestrutura é fundamental para a efetiva fotorredução de $\mathrm{CO}_{2}$.

Os compostos de nanotubos de carbono também atraem um interesse considerável devido às suas propriedades intrínsecas, como notável resistência mecânica, elevada área superficial específica e boa condutividade elétrica. Eles podem assumir comportamento elétrico de semicondutor, semimetais ou metais, dependendo do diâmetro do tubo. Além disso, a presença de e $e^{-} \varpi$ na superfície do nanotubo de carbono permite a fixação de átomos e moléculas que são essenciais para a criação de junções entre duas fases. Assim, os nanotubos de carbono são bons candidatos para o desenvolvimento de heteroestruturas. ${ }^{156,157}$ As heteroestruturas de óxidos metálicos/nanotubos de carbono foram recentemente relatadas como catalisadores efetivos para a geração de $\mathrm{H}_{2}$ a partir da quebra de água, para a fotorredução de $\mathrm{CO}_{2}$ e para a degradação de poluentes orgânicos. ${ }^{158-161}$

Assim como o $\mathrm{CO}_{2}, \mathrm{o} \mathrm{H}_{2}$ também é considerado um combustível com alto potencial para aplicações energéticas. ${ }^{162} \mathrm{O} \mathrm{H}_{2}$ também é considerado um combustível "verde" visto que o seu produto final de combustão é a água. ${ }^{163,164}$ No entanto, o uso bem-sucedido do hidrogênio molecular como combustível, considerando tanto cenários ambientais quanto econômicos, requer o desenvolvimento de processos eficazes de geração de $\mathrm{H}_{2}$ pela quebra da água (water splitting). Como já mencionado, em 1972, Fujishima e Honda ${ }^{8}$ mostraram a decomposição da água para a produção de $\mathrm{H}_{2}$ pela utilização da energia da luz em um sistema fotoeletroquímico contendo $\mathrm{TiO}_{2}$ como ânodo (fotoativado).

A fotólise da água requer semicondutores com $\mathrm{BC}$ de potencial mais negativo em relação ao potencial de redução de $\mathrm{H}^{+}$para $\mathrm{H}_{2}\left(\mathrm{E}^{\mathrm{o}}\right.$ $=0 \mathrm{~V} v s \mathrm{EPH}$ em $\mathrm{pH}=0$ ) e $\mathrm{BV}$ com potencial mais positivo do que o necessário para a oxidação de $\mathrm{H}_{2} \mathrm{O}$ em $\mathrm{O}_{2}\left(\mathrm{E}^{\mathrm{o}}=1,23 \mathrm{~V} v s \mathrm{EPH}\right) .{ }^{165}$ Essa exigência das posições relativas das bandas somada à necessidade de desenvolvimento de fotocatalisadores ativos sob irradiação visível e com maior tempo de vida dos portadores de carga impõe diversos desafios à produção de $\mathrm{H}_{2} \cdot{ }^{166,167}$ Nesse contexto, o desenvolvimento de diferentes tipos de arquiteturas de heteroestruturas de semicondutores com propriedades desejadas tem sido um dos focos científicos principais, especialmente objetivando o melhor aproveitamento da radiação solar.

Existe uma grande variedade de heteroestruturas de semicondutores baseados em óxidos $\left(\mathrm{Fe}_{2} \mathrm{O}_{3}, \mathrm{WO}_{3}, \mathrm{BiVO}_{4}\right),{ }^{168}$ sulfetos $(\mathrm{CdS}, \mathrm{CuS}) \mathrm{e}$ nitretos e oxinitretos ( $\mathrm{TaON}, g-\mathrm{C}_{3} \mathrm{~N}_{4}$ ) ${ }^{168}$ capazes de promover a quebra de moléculas de água para a produção de hidrogênio combustível. ${ }^{169,170}$

Ma e colaboradores ${ }^{171}$ desenvolveram uma heteroestrutura entre $\mathrm{ZnO}$ e $\mathrm{ZnS}$ decorado com nanopartículas de $\mathrm{Au}$ (Au NPs) eficiente para aplicação como fotocatalisador do processo de water splitting. A proporção ótima entre as fases na heteroestruturas apresentou uma alta taxa de geração de $\mathrm{H}_{2}\left(56,81 \mu \mathrm{mol} \cdot \mathrm{h}^{-1} \cdot \mathrm{g}^{-1}\right)$, sendo 345,374 e 11 vezes mais ativo que as fases $\mathrm{ZnO}, \mathrm{ZnS}$ e $\mathrm{ZnO} / \mathrm{ZnS}$, respectivamente. $\mathrm{O}$ aumento da taxa de produção de $\mathrm{H}_{2}$ pode ser atribuída aos efeitos sinérgicos do canal oco (hollow channel) e das Au NPs depositadas. O canal oco cria um novo caminho de migração onde os portadores de carga podem ser transferidos além da superfície externa do fotocatalisador. A deposição de Au NPs na interface entre $\mathrm{ZnO}$ e $\mathrm{ZnS}$ não apenas facilita a migração direcional de portadores de carga por causa da formação da barreira de Schottky, mas também funciona como transporte de elétrons para formar um processo de transferência de esquema-Z, promovendo efetivamente a separação e migração dos transportadores de carga. No entanto, essa heteroestrutura foi ativa apenas sob irradiação visível.

Yin e colaboradores ${ }^{172}$ observaram que a formação da heteroestrutura $\mathrm{CdS} / \mathrm{SrTiO}_{3}$ deslocou a absorção de luz da região ultravioleta para visível e aumentou o tempo de vida dos portadores de carga. Como 
resultado, o $\mathrm{CdS} / \mathrm{SrTiO}_{3}$ apresentou alto desempenho fotocatalítico com taxa de evolução de $\mathrm{H}_{2}$ de $1322 \mu \mathrm{mol} \cdot \mathrm{g}^{-1} \cdot \mathrm{h}^{-1}$, aproximadamente 2,8 e 12,2 vezes maiores do que das fases $\mathrm{CdS}$ e $\mathrm{SrTiO}_{3}$ puras, respectivamente.

$\mathrm{O}$ g- $\mathrm{C}_{3} \mathrm{~N}_{4}$ devido as suas propriedades físico-químicas é um material com alto potencial de aplicação também na área de produção de $\mathrm{H}_{2}$. Esse semicondutor tem sido utilizado combinado com outros semicondutores para deslocar a região de absorção para o visível e aumentar o tempo de vida dos portadores de carga. A Tabela 1 apresenta a atividade fotocatalítica sob condições experimentais de diversas heteroestruturas a base de $\mathrm{g}-\mathrm{C}_{3} \mathrm{~N}_{4}$.

Tabela 1. Atividade fotocatalítica de diferentes heteroestruturas baseadas em g- $\mathrm{C}_{3} \mathrm{~N}_{4}$. Todos os estudos foram feitos a $300 \mathrm{~W}$ de potência e sob radiação visível

\begin{tabular}{ccc}
\hline Heteroestrutura & $\begin{array}{c}\text { Produção de } \mathrm{H}_{2} \\
\left(\mu \mathrm{mol} \cdot \mathrm{g}^{-1} \cdot \mathrm{h}^{-1}\right)\end{array}$ & Referência \\
\hline $\mathrm{g}-\mathrm{C}_{3} \mathrm{~N}_{4} / \mathrm{CoO}$ & 651,3 & 173 \\
$\mathrm{MoS}_{2} / \mathrm{g}-\mathrm{C}_{3} \mathrm{~N}_{4} / \mathrm{GO}$ & 165,00 & 174 \\
$\mathrm{CoTiO}_{3} / \mathrm{g}_{-} \mathrm{C}_{3} \mathrm{~N}_{4}$ & 858,00 & 175 \\
$\mathrm{CoP}-\mathrm{CdS} / \mathrm{g}-\mathrm{C}_{3} \mathrm{~N}_{4}$ & $23.536,00$ & 176 \\
\hline
\end{tabular}

\section{CONSIDERAÇÕES FINAIS}

Os desafios relacionados ao uso de heteroestruturas de semicondutores em processos fotoquímicos são imensos, assim como as suas potencialidades em diferentes e importantes aplicações. Embora diferentes metodologias de preparo de heteroestruturas tenham sido desenvolvidas e aprimoradas nos últimos anos, o desenvolvimento de produtos tecnológicos com esses materiais para serem aplicados em alguns processos fotoquímicos ainda pode ser considerado incipiente. De certa forma esta limitação vem norteando novos trabalhos, que em geral objetivam desenvolver materiais mais eficientes e com o menor custo, tanto no preparo quanto no momento da aplicação. Nesse sentido, os semicondutores baseados em óxidos metálicos apresentam grande potencialidade por apresentarem metodologias de preparo simples e precursores de baixo custo. Além desses materiais, alguns semicondutores com baixo valor de energia de band gap estão sendo utilizados na montagem de heteroestruturas por possibilitarem, por exemplo, o uso de luz solar na fotoativação de diferentes processos, o que torna tais processos mais interessantes do ponto de vista econômico e ambiental.

\section{MATERIAL SUPLEMENTAR}

A Figura 1S utilizada neste trabalho está disponível em http:// quimicanova.sbq.org.br/, na forma de arquivo PDF, com acesso livre.

\section{AGRADECIMENTOS}

Os autores agradecem o apoio financeiro do Ministério da Ciência, Tecnologia, Inovações e Comunicações (através do Programa SisNANO - Sistema Nacional de Laboratórios em Nanotecnologia), Conselho Nacional de Desenvolvimento Científico e Tecnológico (CNPq, Processos n ${ }^{\circ}$ 454438/2014-1, 407497/2018-8, 300247/20133 e 402287/2013-4,), Coordenação para o Aperfeiçoamento de Pessoal de Nível Superior (CAPES), da Fundação de Amparo à Pesquisa do Estado de Minas Gerais (FAPEMIG, Processo nº: APQ-00889-18, da Fundação de Amparo à Pesquisa do Estado de São Paulo (FAPESP, Processos no: 13/13888-0, 15/12304-0, 15/14330-8, 16/09746-3, 18/04558-0 e 18/01258-5) e da Embrapa Rede AgroNano pelo apoio financeiro. Caue Ribeiro também agradece Chinese Academy of
Sciences (CAS) President's International Fellowship Initiative (PIFI) pela CAPES - Alexander von Humboldt Foundation (Experienced Researchers Fellowship, Processo CAPES: 20 88881.145566/2017-1).

\section{REFERÊNCIAS}

1. Serpone, N.; Borgarello, E.; Grätzel, M.; J. Chem. Soc. Chem. Commun. 1984, 342 .

2. Nurdiwijayanto, L.; Wu, J.; Sakai, N.; Ma, R.; Ebina, Y.; Sasaki, T.; ACS Appl. Energy Mater. 2018, 1, 6912.

3. Moniz, S. J. A.; Shevlin, S. A.; Martin, D. J.; Guo, Z.-X.; Tang, J.; Energy Environ. Sci. 2015, 8, 731.

4. Wang, H.; Zhang, L.; Chen, Z.; Hu, J.; Li, S.; Wang, Z.; Liu, J.; Wang, X.; Chem. Soc. Rev. 2014, 43, 5234.

5. Mourão, H. a. J. L.; Avansi Junior, W.; Ribeiro, C.; Mater. Chem. Phys. 2012, 135, 524

6. Zhang, J.; Xu, Q.; Feng, Z.; Li, M.; Li, C.; Angew. Chem., Int. Ed. Engl. 2008, 47,1766

7. Kong, L.; Jiang, Z.; Lai, H. H.; Nicholls, R. J.; Xiao, T.; Jones, M. O.; Edwards, P. P.; J. Catal. 2012, 293, 116.

8. Fujishima, A.; Honda, K.; Nature 1972, 238, 37.

9. Kittel, C.; Introdução a Física Do Estado Solido, $5^{\circ}$ ed.; Guanabara Dois: Rio de Janeiro: 1978, cap. 8.

10. Yang, X.; Wang, D.; ACS Appl. Energy Mater. 2018, 1, 6657.

11. Shriver, D. F.; Atkins, P. W.; Química Inorgânica, $3^{\text {a }}$ ed., Bookman; Porto Alegre: 2003, cap. 3.

12. Baccaro, A. L. B.; Gutz, I. G. R.; Quim. Nova 2018, 41, 326.

13. Rogers, B.; Pennathur, S.; Adams, J.; Nanotechnology: Understanding Small Systems, $3^{\text {rd }}$ ed., 2014.

14. Dimitrijev, S.; Principles of semiconductor devices, $2^{\text {nd }}$ ed., University, O.: New York, 2012.

15. Willian D. Callister, J.; Rethwisch, D. G.; Ciência e Engenharia dos Materiais - uma Introdução, $8^{\mathrm{a}}$ ed.; LTC, 2012, cap. 18.

16. Housecroft, C. E.; Sharpe, A. G.; Inorganic Chemistry, $4^{\text {th }}$ ed., Pearson: London, 2012.

17. De Mendonça, V. R.; Lopes, O. F.; Fregonesi, R. P.; Giraldi, T. R.; Ribeiro, C.; Appl. Surf. Sci. 2014, 298, 182.

18. Low, J.; Yu, J.; Jaroniec, M.; Wageh, S.; Al-Ghamdi, A. A.; Adv. Mater. 2017, 29, 1601694.

19. Jang, J. S.; Kim, H. G.; Lee, J. S.; Catal. Today 2012, 185, 270.

20. Chen, H.; Chen, S.; Quan, X.; Zhang, Y.; Environ. Sci. Technol. 2010, $44,451$.

21. Bard, A. J.; J. Photochem. 1979, 10, 59.

22. Tada, H.; Mitsui, T.; Kiyonaga, T.; Akita, T.; Tanaka, K.; Nat. Mater. 2006, 5,782 .

23. Theerthagiri, J.; Chandrasekaran, S.; Salla, S.; Elakkiya, V.; Senthil, R. A.; Nithyadharseni, P.; Maiyalagang, T.; KavinMicheal; A. Ayeshamariam; Valan Arasu, M.; Naif Abdullah Al-Dhabi; Hyun-Seok Kim; J. Solid State Chem. 2018, 267, 35.

24. da Silva, G. T. S. T.; Carvalho, K. T. G.; Lopes, O. F.; Ribeiro, C.; Appl. Catal., B 2017, 216, 70.

25. Xiao, Y.; Peng, Z. Y.; Zhang, S.; Jiang, Y. H.; Jing, X.; Yang, X. Y.; Zhang, J. M.; Ni, L.; J. Mater. Sci. 2019, 54, 9573.

26. Zhou, W.; Yin, Z.; Du, Y.; Huang, X.; Zeng, Z.; Fan, Z.; Liu, H.; Wang, J.; Zhang, H.; Small 2013, 9, 140.

27. Amirav, L.; Alivisatos, A. P.; J. Phys. Chem. Lett. 2010, 1, 1051.

28. Zheng, Y.; Zheng, L.; Zhan, Y; Lin, X.; Zheng, Q.; Wei, K.; Inorg. Chem. 2007, 46, 6980 .

29. Alves de Castro, I.; Ariane de Oliveira, J.; Cristina Paris, E.; Regina Giraldi, T.; Ribeiro, C.; Ceram. Int. 2015, 41, 3502.

30. Fu, Q.; Wang, X.; Zhou, J.; Xia, J.; Zeng, Q.; Lv, D.; Zhu, C.; Wang, X.; Shen, Y.; Li, X.; Hua, Y.; Liu, F.; Shen, Z.; Jin, C.; Liu, Z.; Chem. Mater. 2018, 30, 4001 
31. Zhang, L.; Niu, C. G.; Liang, C.; Wen, X. J.; Huang, D. W.; Guo, H.; Zhao, X. F.; Zeng, G. M.; Chem. Eng. J. 2018, 352, 863.

32. Mendoza-Mendoza, E.; Nuñez-Briones, A. G.; García-Cerda, L. A.; Peralta-Rodríguez, R. D.; Montes-Luna, A. J.; Ceram. Int. 2018, 44, 6176.

33. Yang, G., Yang, B., Xiao, T., \& Yan, Z.; App. Surf. Sci. 2013, 283, 402.

34. Su, R.; Bechstein, R.; S $\varnothing$, L.; Vang, R. T.; Sillassen, M.; Esbjornsson, B.; Palmqvist, A.; Besenbacher, F.; J Phys. Chem C. 2011, 115, 24287.

35. Ohno, T.; Sarukawa, K.; Tokieda, K.; Matsumura, M.; J. Catal. 2001, $203,82$.

36. Lopes, O. F.; Carvalho, K. T. G.; Nogueira, A. E.; Avansi, W.; Ribeiro, C.; Appl. Catal., B 2016, 188, 87.

37. Liu, Z.; Wang, G.; Chen, H. S.; Yang, P.; Chem. Commun. 2018, 54, 4720.

38. Cai, L.; Yao, J.; Li, J.; Zhang, Y.; Wei, Y.; J. Alloys Compd. 2019, 783, 300.

39. Siedl, N.; Baumann, S. O.; Elser, M. J.; Diwald, O.; J. Phys. Chem. C. 2012, 116, 22967.

40. Carvalho, K. T. G.; Nogueira, A. E.; Lopes, O. F.; Byzynski, G.; Ribeiro, C.; Ceram. Int. 2016, 43, 3521.

41. Nossol, A. B.; Rosa, S. M.; Nossol, E.; Zarbin, A. J.; Peralta-Zamora, P.; Quim. Nova. 2016, 39, 686.

42. Lopes, O. F.; Carvalho, K. T. G.; Avansi, W.; Ribeiro, C.; J. Phys. Chem. C 2017, 121, 13747.

43. Liu, D.; Wang, J.; Wang, Y.; Zhu, Y.; Catal. Sci. Technol. 2018, 8, 3278.

44. Cao, Y.; Li, Q.; Xing, Y.; Zong, L.; Yang, J.; Appl. Surf. Sci. 2015, 341, 190.

45. Pei, Y.; Li, X.; Chu, H.; Ge, Y.; Dong, P.; Baines, R.; Pei, L.; Ye, M.; Shen, J.; Talanta. 2017, 165, 44.

46. da Silva, G. T. S. T.; Carvalho, K. T. G.; Lopes, O. F.; Ribeiro, C.; Appl. Catal., B 2017, 216, 70 .

47. Hao, L. X.; Chen, G.; Yu, Y. G.; Zhou, Y. S.; Han, Z. H.; Liu, Y.; Int. J. Hydrogen Energy 2014, 39, 14479.

48. Khan, I.; Ibrahim, A. A.; Sohail, M.; Qurashi, A.; Ultrason. Sonochem. 2017, 37, 669 .

49. Raimundo, C. M.; Tese de doutorado, Universidade Estadual de Campinas, Brasil, 2011.

50. Dewil, R.; Mantzavinos, D.; Poulios, I.; Rodrigo, M. A.; J. Environ. Manage. 2017, 195, 93.

51. Grätzel, M.; Nature 2001, 414, 338.

52. Hoffmann, M. R.; Martin, S. T.; Choi, W.; Bahnemann, D. W.; Chem. Rev. 1995, 95, 69.

53. Lopes, O. F.; De Mendonça, V. R.; Silva, F. B. F.; Paris, E. C.; Ribeiro, C.; Quim. Nova 2015, 38, 106.

54. Mourão, H. A. J. L.; De Mendonça, V. R.; Malagutti, A. R.; Ribeiro, C.; Quim. Nova 2009, 32, 2181.

55. Teoh, W. Y.; Scott, J. A.; Amal, R.; J. Phys. Chem. Lett. 2012, 3, 629.

56. Wang, H.-W.; Lin, H.-C.; Kuo, C.-H.; Cheng, Y.-L.; Yeh, Y.-C.; J. Phys. Chem. Solids 2008, 69, 633.

57. Ni, M.; Leung, M. K. H.; Leung, D. Y. C.; Sumathy, K.; Leung, M. K. H.; Renewable Sustainable Energy Rev. 2007, 11, 401.

58. Zong, X.; Wang, L.; J. Photochem. Photobiol., C 2014, 18, 32.

59. Kim, I. Y.; Jo, Y. K.; Lee, J. M.; Wang, L.; Hwang, S. J.; J. Phys. Chem. Lett. 2014, 5, 4149.

60. Nakata, K.; Fujishima, A.; J. Photochem. Photobiol., C 2012, 13, 169.

61. Wu, W.; Jiang, C.; Roy, V. A. L.. Nanoscale 2014, 7, 38.

62. Wang, P.; Tang, H.; Ao, Y.; Wang, C.; Hou, J.; Qian, J.; Li, Y.; J. Alloys Compd. 2016, 688, 1.

63. Yu, C.; Zhou, W.; Yu, J. C.; Liu, H.; Wei, L.; Chin. J. Catal. 2014, 35, 1609.

64. Chetia, T. R.; Ansari, M. S.; Qureshi, M.; J. Mater. Chem. A 2016, 4, 5528.
65. Huang, H.; Liu, L.; Zhang, Y.; Tian, N.; J. Alloys Compd. 2015, 619, 807.

66. Niraula, M.; Adhikari, S.; Lee, D. Y.; Kim, E. K.; Yoon, S. J.; Dhungel, S. K.; Lee, W.; Shrestha, N. K.; Han, S. H.; Chem. Phys. Lett. 2014, 593 , 193.

67. Li, Q.; Zhang, N.; Yang, Y.; Wang, G.; Ng, D. H. L. Langmuir 2014, 30, 8965.

68. Paul, K. K.; Sreekanth, N.; Biroju, R. K.; Narayanan, T. N.; Giri, P. K.; Sol. Energy Mater. Sol. Cells 2018, 185, 364.

69. Prakash Bhoi, Y.; Behera, C.; Majhi, D.; Equeenuddin, S. M.; Mishra, B. G.; New J. Chem. 2018, 42, 281.

70. Kumar, A.; Sharma, G.; Naushad, M.; Kumar, A.; Kalia, S.; Guo, C.;. J. Photochem. Photobiol., A 2017, 337, 118.

71. Tang, L.; Wang, J.-J.; Jia, C.-T.; Lv, G.-X.; Xu, G.; Li, W.-T.; Wang, L.; Zhang, J.-Y.; Wu, M.-H. Appl. Catal., B 2017, 587.

72. Lei, Z.-D.; Wang, J.-J.; Wang, L.; Yang, X.-Y.; Xu, G.; Tang, L.; J. Hazard. Mater. 2016, 312, 298.

73. Lin, X.; Xu, D.; Zheng, J.; Song, M.; Che, G.; Wang, Y.; Yang, Y.; Liu, C.; Zhao, L.; Chang, L.; J. Alloys Compd. 2016, 688, 891.

74. Lu, H.; Hao, Q.; Chen, T.; Zhang, L.; Chen, D.; Ma, C.; Yao, W.; Zhu, Y.; Appl. Catal., B 2018, 237, 59.

75. Liu, D.; Cai, W.; Wang, Y.; Zhu, Y.; Appl. Catal., B 2018, 236, 205.

76. Liao, G.; Chen, S.; Quan, X.; Yu, H.; Zhao, H.; J. Mater. Chem. 2012, 22, 2721.

77. Wen, J.; Xie, J.; Chen, X.; Li, X; Appl. Surf. Sci. 2017, 391, 72.

78. Kumar, S.; Tonda, S.; Baruah, A.; Kumar, B.; Shanker, V.; Dalton Trans. 2014, 43, 16105.

79. Zhang, R.; Ma, M.; Zhang, Q.; Dong, F.; Zhou, Y.; Appl. Catal., B 2018, $235,17$.

80. Wang, M.; Wang, H.; Ren, Y.; Wang, C.; Weng, Z.; Yue, B.; He, H.; Nanomaterials 2018, 8, 427.

81. Xu, Y.; Chen, Y.; Fu, W. F.; Appl. Catal., B 2018, 236, 176.

82. Wang, Y.; Tan, G.; Liu, T.; Su, Y.; Ren, H.; Zhang, X. L.; Xia, A.; Lv, L.; Liu, Y.; Appl. Catal., B 2018, 234, 37.

83. Malato, S.; Maldonado, M. I.; Fernández-Ibáñez, P.; Oller, I.; Polo, I.; Sánchez-Moreno, R.; Mater. Sci. Semicond. Process. 2016, 42, 15.

84. Spasiano, D.; Marotta, R.; Malato, S.; Fernandez-Ibañez, P.; Di Somma, I.; Appl. Catal., B 2015, 170-171, 90 .

85. Barakat, M. A.; Arab. J. Chem. 2011, 4, 361.

86. Herrmann, J.-M.; Catal. Today 1999, 53, 115.

87. Pradhan, D.; Sukla, L. B.; Sawyer, M.; Rahman, P. K. S. M.; J. Ind. Eng. Chem. 2017, 55, 1.

88. Nogueira, A. E.; Giroto, A. S.; Neto, A. B. S.; Ribeiro, C.; Colloids Surf., A 2016, 498, 161.

89. Gao, Y.; Liu, R.; Appl. Water Sci. 2017, 7, 3625.

90. Anderson, R. A.; Regul. Toxicol. Pharmacol. 1997, 26, 35.

91. Vinuth, M.; Naik, H. S. B.; sekhar, K. C.; Manjanna, J.; Vinoda, B. M.; Procedia Earth Planet. Sci. 2015, 11, 275.

92. Wang, X.; Pehkonen, S. O.; Ray, A. K.; Ind. Eng. Chem. Res. 2004, 43, 1665.

93. Djellabi, R.; Ghorab, F. M.; Nouacer, S.; Smara, A.; Khireddine, O.; Mater. Lett. 2016, 176, 106.

94. Nogueira, A. E.; Lopes, O. F.; Neto, A. B. S.; Ribeiro, C.; Chem. Eng. J. 2017, 312, 220.

95. Dong, G.; Zhang, L.; J. Phys. Chem. C 2013, 117, 4062.

96. Li, Y.; Liu, Z.; Wu, Y.; Chen, J.; Zhao, J.; Jin, F.; Na, P.; Appl. Catal., B 2018, 224, 508.

97. Woan, K.; Pyrgiotakis, G.; Sigmund, W.; Adv. Mater. 2009, 21, 2233.

98. Tsai, Y. P.; Doong, R. A.; Yang, J. C.; Wu, Y. J.; J. Chem. Technol. Biotechnol. 2011, 86, 949.

99. Guan, X.; Du, J.; Meng, X.; Sun, Y.; Sun, B.; Hu, Q.; J. Hazard. Mater. 2012, $215,1$. 
100. Shafiee, M. A. M.; Jafari, A. A.; Int. J. Environ. Sci. Technol. 2017, 16, 463.

101. Byrne, J. A.; Dunlop, P. S. M.; Hamilton, J. W. J.; Fernández-Ibáñez, P.; Polo-López, I.; Sharma, P. K.; Vennard, A. S. M.; Molecules 2015, 20, 5574.

102. Venkata, P.; Reddy, L.; Kavitha, B.; Reddy, A. K.; Kim, K.-H.; Environ. Res. 2017, 154, 296.

103. Matsunaga, T.; Tomoda, R.; Nakajima, T.; Wake, H.; FEMS Microbiol. Lett. 1985, 29, 211.

104. Byrne, J. A.; Fernandez-Ibañez, P. A.; Dunlop, P. S. M.; Alrousan, D. M. A.; Hamilton, J. W. J.; Int. J. Photoenergy 2011, 2011

105. Cho, M.; Chung, H.; Choi, W.; Yoon, J.; Water Res. 2004, 38, 1069.

106. Robertson, P. K. J.; Robertson, J. M. C.; Bahnemann, D. W.; J. Hazard. Mater. 2011, 211, 161.

107. Jia, Y.; Zhan, S.; Ma, S.; Zhou, Q.; ACS Appl. Mater. Interfaces 2016, 8, 6841.

108. Li, G.; Nie, X.; Chen, J.; Jiang, Q.; An, T.; Wong, P. K.; Zhang, H.; Zhao, H.; Yamashita, H.; Water Res. 2015, 86, 17.

109. Li, Y.; Ding, H.; Mao, K.; Wang, D.; Wang, Q.; Zhang, W.; CLEAN Soil, Air, Water 2015, 43, 512.

110. Wang, G.; Feng, W.; Zeng, X.; Wang, Z.; Feng, C.; McCarthy, D. T.; Deletic, A.; Zhang, X.; Water Res. 2016, 94, 363.

111. Ma, S.; Zhan, S.; Jia, Y.; Zhou, Q.; ACS Appl. Mater. Interfaces 2015, 7, 21875 .

112. Ju, P.; Wang, Y.; Sun, Y.; Zhang, D.; Dalton Trans. 2016, 45, 4588.

113. Gan, H.; Zhang, G.; Huang, H.; J. Hazard. Mater. 2013, 250-251, 131.

114. Xiang, Z.; Wang, Y.; Zhang, D.; Ju, P.; J. Ind. Eng. Chem. 2016, 40, 83.

115. Mo, J.; Zhang, Y.; Xu, Q.; Lamson, J. J.; Zhao, R.; Atmos. Environ. 2009, 43, 2229

116. Lin, L.; Chai, Y.; Zhao, B.; Wei, W.; He, D.; He, B.; Tang, Q.; Open J. Inorg. Chem. 2013, 3, 14

117. Bianchi, C. L.; Gatto, S.; Pirola, C.; Naldoni, A.; Di Michele, A.; Cerrato, G.; Crocellà, V.; Capucci, V.; Appl. Catal., B 2014, 146, 123.

118. Jafari, A. J.; Kalantari, R. R.; Kermani, M.; Firooz, M. H.; Data Brief 2018, 20, 490 .

119. Xin, Y.; Chen, Q.; Zhang, G.; J. Alloys Compd. 2018, 751, 231.

120. Kong, J.; Rui, Z.; Ji, H.; Ind. Eng. Chem. Res. 2017, 56, 9999.

121. Sun, J.; Li, X.; Zhao, Q.; Ke, J.; Zhang, D.; J. Phys. Chem. C 2014, 118 , 10113

122. Katsumata, K. I.; Motoyoshi, R.; Matsushita, N.; Okada, K.; J. Hazard. Mater. 2013, 260, 475.

123. Zou, X.; Dong, Y.; Zhang, X.; Cui, Y.; Ou, X.; Qi, X.; Appl. Surf. Sci. 2017, 391, 525.

124. Shayegan, Z.; Lee, C. S.; Haghighat, F; Chem. Eng. J. 2018, 334, 2408.

125. Ângelo, J.; Andrade, L.; Madeira, L. M.; Mendes, A.; J. Environ. Manage. 2013, 129, 522 .

126. Nikokavoura, A.; Trapalis, C.; Appl. Surf. Sci. 2018, 430, 18.

127. Li, X.; Yan, X.; Zuo, S.; Lu, X.; Luo, S.; Li, Z.; Yao, C.; Ni, C.; Chem. Eng. J. 2017, 320, 211

128. Bowering, N.; Walker, G. S.; Harrison, P. G.; Appl. Catal., B 2006, 62, 208.

129. Li, X.; Shi, H.; Wang, T.; Zhang, Y.; Lu, X.; Zuo, S.; Li, Z.; Yao, C.; J. Taiwan Inst. Chem. Eng. 2018, 89, 119

130. Lasek, J.; Yu, Y.; Wu, J. C. S.; J. Photochem. Photobiol., C 2013, 14, 29.

131. Ou, M.; Wan, S.; Zhong, Q.; Zhang, S.; Song, Y.; Guo, L.; Cai, W.; Appl. Catal., B 2018, 221, 97.

132. Ma, J.; Wang, C.; He, H.; Appl. Catal., B 2016, 184, 28.

133. Luévano-Hipólito, E.; Martínez-De La Cruz, A.; López-Cuellar, E.; Yu, Q. L.; Brouwers, H. J. H.; Mater. Chem. Phys. 2014, 148, 208.

134. Huy, T. H.; Bui, D. P.; Kang, F.; Wang, Y. F.; Liu, S. H.; Thi, C. M.; You, S. J.; Chang, G. M.; Pham, V. V.; Chemosphere 2019, 215, 323.

135. Liu, D.; Chen, D.; Li, N.; Xu, Q.; Li, H.; He, J.; Lu, J.; Appl. Catal., B 2019, 243,576
136. Wan, S.; Ou, M.; Cai, W.; Zhang, S.; Zhong, Q.; J. Phys. Chem. Solids 2018, 122, 239

137. Wan, S.; Zhong, Q.; Ou, M.; Zhang, S.; J. Mater. Sci. 2017, 52, 11453.

138. Zhang, Q.; Huang, Y.; Peng, S.; Zhang, Y.; Shen, Z.; Cao, J.; Ho, W.; Cheng, S.; Pui, D. Y. H.; Appl. Catal., B 2017, 204, 346.

139. Morris, A. J.; Meyer, G. J.; Fujita, E.; Acc. Chem. Res. 2009, 42, 1983. 140. Lim, C. H.; Holder, A. M.; Hynes, J. T.; Musgrave, C. B.; J. Phys. Chem. Lett. 2015, 6, 5078 .

141. Mondal, B.; Song, J.; Neese, F.; Ye, S.; Curr. Opin. Chem. Biol. 2015, $25,103$.

142. Li, K.; Peng, B.; Peng, T.; ACS Catal. 2016, 6, 7485.

143. Mao, Z.; Chen, J.; Yang, Y.; Wang, D.; Bie, L.; Fahlman, B. D.; ACS Appl. Mater. Interfaces 2017, 9, 12427.

144. Habisreutinger, S. N.; Schmidt-Mende, L.; Stolarczyk, J. K.; Angew. Chem., Int. Ed. 2013, 52, 7372.

145. D’Alessandro, D. M.; Smit, B.; Long, J. R.; Angew. Chem., Int. Ed. 2010, 49.

146. Ma, Y.; Wang, X.; Jia, Y.; Chen, X.; Han, H.; Li, C.; Chem. Rev. 2014 $114,9987$.

147. Chang, X.; Wang, T.; Gong, J.; Energy Environ. Sci. 2016, 9, 2177.

148. Han, S.; Chen, Y.; Abanades, S.; Zhang, Z.; J. Energy Chem. 2017, 26, 743.

149. Lingampalli, S. R.; Ayyub, M. M.; Rao, C. N. R.; ACS Omega 2017, 2 , 2740 .

150. Kwon, S.; Liao, P.; Stair, P. C.; Snurr, R. Q.; Catal. Sci. Technol. 2016, 6,7885 .

151. Li, H.; Wu, X.; Wang, J.; Gao, Y.; Li, L.; Shih, K.; Int. J. Hydrogen Energy 2016, 41, 8479.

152. Li, Q.; Zong, L.; Li, C.; Yang, J.; Appl. Surf. Sci. 2014, 314, 458.

153. Xie, S.; Wang, Y.; Zhang, Q.; Deng, W.; Wang, Y.; ACS Catal. 2014, 4, 3644

154. Sun, Z.; Fischer, J. M. T. A.; Li, Q.; Hu, J.; Tang, Q.; Wang, H.; Wu, Z.; Hankel, M.; Searles, D. J.; Wang, L.; Appl. Catal., B 2017, 216, 146.

155. Wang, C.; Thompson, R. L.; Baltrus, J.; Matranga, C.; J. Phys. Chem. Lett. 2010, 1, 48.

156. Yan, Y.; Miao, J.; Yang, Z.; Xiao, F.-X.; Yang, H. Bin; Liu, B.; Yang, Y.; Chem. Soc. Rev. 2015, 44, 3295.

157. Price, G. J.; Nawaz, M.; Yasin, T.; Bibi, S.; Ultrason. Sonochem. 2016, $40,123$.

158. Lashgari, M.; Soodi, S.; Zeinalkhani, P.; J. CO2 Util. 2017, 18, 89.

159. Sampaio, M. J.; Benyounes, A.; Serp, P.; Faria, J. L.; Silva, C. G.; Appl. Catal., A 2018, 551, 71.

160. Lv, J.; Li, D.; Dai, K.; Liang, C.; Jiang, D.; Lu, L.; Zhu, G.; Mater Chem. Phys. 2017, 186, 372.

161. Chung, K.-H.; Jeong, S.; Kim, B.-J.; Kim, J.-S.; Park, Y.-K.; Jung, S.-C.; Int. J. Hydrogen Energy 2017, 43, 5873.

162. Zhang, P.; Wang, T.; Gong, J.; Chem. 2018, 4, 223.

163. Tee, S. Y.; Win, K. Y.; Teo, W. S.; Koh, L. D.; Liu, S.; Teng, C. P.; Han, M. Y.; Adv. Sci. 2017, 4, 1600337.

164. Christopher, K., Dimitrios, R.; Energy Environ. Sci. 2012, 5, 6640.

165. Khine, S. S.; Hisatomi, T.; Domen, K.; J.Japan Pet Inst. 2013, 56, 280.

166. Kudo, A.; Catal. Surv. Asia 2003, 7, 31.

167. Maeda, K.; Domen, K.; J. Phys. Chem. Lett. 2010 1, 2655.

168. Afroz, K.; Moniruddin, M.; Bakranov, N.; Kudaibergenov, S.; Nuraje, N.; J. Mater. Chem A. 2018, 6, 21696.

169. Chen, S.; Thind, S. S.; Chen, A.; Electrochem. Commun. 2016, 63, 10 .

170. Balogun, M. S.; Huang, Y.; Qiu, W.; Yang, H.; Ji, H.; Tong, Y.; Mater. Today 2017, 20, 425 .

171. Ma, D.; Shi, J. W.; Sun, D.; Zou, Y.; Cheng, L.; He, C.; Wang, H.; Niu, C.; Wang, L.; Applied Catal. B, Environ. 2019, 244, 748.

172. Yin, X. L.; Li, L. L.; Li, D. C.; Wei, D. H.; Hu, C. C.; Dou, J. M.; J. Colloid Interface Sci. 2019, 536, 694. 
173. Mao, Z.; Chen, J.; Yang, Y.; Wang, D.; Bie, L.; Fahlman, B. D.; ACS Appl. Mater. Interfaces. 2017, 9, 12427.

174. Wang, M.; Ju, P.; Li, J.; Zhao, Y.; Han, X.; Hao, Z.; ACS Sustainable Chem. Eng. 2017, 5, 7878.
175. Ye, R., Fang, H., Zheng, Y. Z., Li, N., Wang, Y., \& Tao, X.; ACS Appl. Mater. Interfaces 2016, 8, 13879.

176. Wang, P.; Wu, T.; Wang, C.; Hou, J.; Qian, J.; Ao, Y.; ACS Sustainable Chem. Eng. 2017, 5, 7670. 